\title{
Evolution of Waste Iron Rust into a-Fe203/CNF and a-Fe203/PANI Composites as an Efficient Positive Electrode for Sustainable Hybrid Super-capacitor
}

Darpan Vijaykumar Bhuse ( $\sim$ bhusedarpan@gmail.com )

Institute of Science Nagpur https://orcid.org/0000-0003-4965-741X

Vijaykumar M Bhuse

Institute of Science Nagpur

Ramdas G Atram

Institute of Science Nagpur

Rounak R Atram

Nagpur University: Rashtrasant Tukadoji Maharaj Nagpur University

Subhash B Kondawar

Nagpur University: Rashtrasant Tukadoji Maharaj Nagpur University

Research Article

Keywords: Supercapacitor, Cyclic Voltammetry, Iron oxide, Electrospinning, PANI

Posted Date: February 17th, 2021

DOI: https://doi.org/10.21203/rs.3.rs-202258/v1

License: (c) (i) This work is licensed under a Creative Commons Attribution 4.0 International License.

Read Full License

Version of Record: A version of this preprint was published at Journal of Materials Science: Materials in Electronics on April 24th, 2021. See the published version at https://doi.org/10.1007/s10854-021-05955$\mathrm{x}$. 


\title{
Evolution of waste iron rust into $\alpha-\mathrm{Fe}_{2} \mathrm{O}_{3} / \mathrm{CNF}$ and $\alpha-\mathrm{Fe}_{2} \mathrm{O}_{3} / \mathrm{PANI}$ composites as an efficient positive electrode for sustainable hybrid super- capacitor
}

\author{
Darpan V. Bhuse ${ }^{a *}$, Vijaykumar M. Bhuse ${ }^{a}$, Ramdas G. Atram ${ }^{b}$, Rounak R. Atram ${ }^{c}$, \\ Subhash B. Kondawar ${ }^{\mathrm{c}}$ \\ ${ }^{a}$ Energy Materials Research Laboratory, Department of Chemistry, Government Institute of Science, \\ Nagpur - 440001, India. \\ ${ }^{\mathrm{b}}$ Department of Physics, Government Institute of Science, Nagpur - 440001, India, \\ ${ }^{c}$ Polymer and Nanotechnology Laboratory, Department of Physics, Rashtrasant Tukdoji Maharaj \\ Nagpur University, Nagpur - 440033, India \\ *Corresponding Author Email: \\ bhusedarpan@gmail.com (D.V. Bhuse)
}

\begin{abstract}
:
A green and sustainable approach to recycle the waste iron rust into a valuable $\alpha$ modification of $\mathrm{Fe}_{2} \mathrm{O}_{3}$ via simple grinding and calcination for application in hybrid supercapacitor is reported. The $\alpha-\mathrm{Fe}_{2} \mathrm{O}_{3}$ was coupled with conducting polymer carbon nanofibers (CNF) and Poly aniline (PANI) to form composite hybrid supercapacitor electrode materials. The conventional hydrothermal, electro-spinning processes were used to prepare composites. X-ray diffraction, Transmission Electron Microscopy (TEM), High Resolution Transmission Electron Microscopy (HRTEM), Selected Area Electron Diffraction (SAED), Scanning Electron Microscopy and Energy Dispersive X-Ray spectroscopy were used to study the structural, morphological and compositional properties of as synthesised $\alpha-\mathrm{Fe}_{2} \mathrm{O}_{3}$ and its composites with $\mathrm{CNF}$ and PANI. The $\alpha-\mathrm{Fe}_{2} \mathrm{O}_{3} / \mathrm{CNF}$ and $\alpha-\mathrm{Fe}_{2} \mathrm{O}_{3} / \mathrm{PANI}$ composites coated on carbon rod were used as electrodes in a three-electrode system to study Electrochemical Impedance Spectroscopy, Cyclic Voltammetry and Galvanostatic Charge-Discharge in $1 \mathrm{M}$ $\mathrm{H}_{2} \mathrm{SO}_{4}$. It is observed that $\alpha-\mathrm{Fe}_{2} \mathrm{O}_{3} / \mathrm{PANI}$ exhibit higher response as against $\alpha-\mathrm{Fe}_{2} \mathrm{O}_{3} / \mathrm{CNF}$ with
\end{abstract}


respect to specific capacitance; $192.29 \mathrm{Fg}^{-1}\left(88.88 \mathrm{Fg}^{-1}\right)$, energy density; $11.28 \mathrm{WhKg}^{-1}(3.084$ $\left.\mathrm{WhKg}^{-1}\right)$ power density; $162.44 \mathrm{Wkg}^{-1}\left(69.39 \mathrm{Wkg}^{-1}\right)$ with capacitance retention of $80 \%(75 \%)$. The heavy dispersion of $\alpha-\mathrm{Fe}_{2} \mathrm{O}_{3}$ over long CNF and PANI fibres with intimate contact resulted in abundant active sites for electrochemical reactions leading to obtained result. The rust derived $\alpha-\mathrm{Fe}_{2} \mathrm{O}_{3}$ with PANI offer excellent stability to act as potential candidate for sustainable hybrid supercapacitor application.

\section{Keywords: Supercapacitor, Cyclic Voltammetry, Iron oxide, Electrospinning, PANI}

\section{Introduction}

The past few decades have witnessed a rapid development in industrial automation, transportation and huge upsurge of modern household appliances. Ever growing industrialization and urbanization however, demands huge amount of electrical energy to work with [1]. Today, most of the energy demands are fulfilled by utilizing non-renewable resources. The renewable energy resources though clean, eco-friendly, plentily available, needs an efficient harvesting system to use. The utilization of former resources mostly leads to depletion and eventually finish of the reservoirs, global warming, pollution and climate change [2]. Whatever be the source of energy, the smart utilization strategy needs an efficient and clean energy storage device so that stored energy can be used as buffer power. With the global concern about the depleting fossil fuels and its post use environmental implications, the development of efficient and clean energy devices utilizing natural materials and a greener synthetic approach has become a challenge to the electrochemists [3,4]. Recently, a lot of interest in research is developed to fabricate energy storage materials for use in batteries, supercapacitors and fuel cells. Among them, supercapacitor have emerged as an eco-friendly and safe means of energy storage device due to its characteristics such as comparatively small size, high power density $\left(5-10 \mathrm{kWkg}^{-1}\right)$, long cycle life (>5,00,000 cycles), long shelf life, high efficiency $(95 \%)$, wide operating temperature range $(-40$ to $+70 \mathrm{C})$ etc. It is being considered as a future's energy storage system that probably complements or even replace conventional batteries and fuel cells [5].

The basic energy storage mechanism in supercapacitor involves either charge separation at the electrode-electrolyte interface (electric double layer capacitors, EDLC) or the Faradic redox reactions between the electrolyte and electro-active surface of the electrode material (pseudo capacitors). The carbon-based materials such as graphene, carbon nanofibers, activated carbon 
and carbon nanotubes serve as the main electrode materials in EDLC [6,7]. Among them, one dimensional carbon mesoporous nanofibers are popular [8].

So far, much effort has been devoted to develop carbon fibers using verities of methods. These methods involve more or less complexity in preparation process and costs high [9]. One of the methods, electrospinning method, working under the precisely controlled conditions, has emerged as a versatile, efficient, continuous and industrially viable method to evolve long nanofibers with different morphology having extremely high aspect ratio and large surface area to volume ratio [10]. Such fibers are highly desirable for use in energy storage applications since they exhibit transportation directionally and short ionic transport lengths [11]. The hydrothermal method, on the other hand, is facile, low-cost method that has advantages such as high yield of the products, control over morphology and reproducibility. So far, a number of metal oxides and hydroxides have been synthesized using hydrothermal technique for use as electrode materials in supercapacitors [12].

The supercapacitors based on EDLC exhibits long cycle life but produce relatively low specific capacitance, whereas, pseudo-capacitor have high specific capacitance but shows slow charge kinetics [13]. The hybrid capacitor, comprising of EDLC and pseudo-capacitor, combine their advantages, namely high energy and power densities and long cycle life. The metal oxides coupled conducting polymers are often employed as pseudo capacitor electrode materials [14]. A huge research literature is available on synthesis of nanofibers and or polymer coupled metal oxides exhibiting better performance in supercapacitance. For instance, electro spun- $\mathrm{TiO}_{2} / \mathrm{CNF}$ exhibited a high specific capacitance $280.3 \mathrm{Fg}^{-1}$ at current density $1 \mathrm{Ag}^{-1}[15]$, hydrothermally grown $\mathrm{V}_{2} \mathrm{O}_{5} / \mathrm{CNF}$ composite exhibits a high capacitance of $227 \mathrm{~F} \mathrm{~g}^{-1}$ for at current density $1 \mathrm{~A} \mathrm{~g}^{-1}[16]$, Zhi et al could achieve specific capacitance of $311 \mathrm{Fg}^{-1}$ at scan rate of $2 \mathrm{mV} / \mathrm{s}$ for $\mathrm{MnO}_{2} / \mathrm{CNF}$ [17], while $\mathrm{ZnO} / \mathrm{CNF}$ displayed specific capacitance of 178.2 $\mathrm{Fg}^{-1}$ as reported by Kim et al [18]. Among oxides, iron oxide $\left(\mathrm{Fe}_{2} \mathrm{O}_{3}\right)$ is considered as an important electrochemical electrode materials due to i) its existence in several morphologies and crystallographic modifications [19], ii) ease in variations in oxidation state $\left(\mathrm{Fe}^{+2} \leftrightarrow \mathrm{Fe}^{+3}\right)$ iii) outstanding theoretical specific capacitance $\left(3625 \mathrm{~F} \mathrm{~g} \mathrm{~g}^{-1}\right)$, iv) high thermal stability v) high corrosion resistance, vi) abundance in nature and environmental friendliness[20,21,22]. and vii) use as positive as well as negative electrode. Like many other electrodes, $\mathrm{Fe}_{2} \mathrm{O}_{3}$, also suffers from poor electrical conductivity leading to lower capability and cycling stability [23]. However, the electrical conductivity can be improved by introducing carbon/ conducting polymer materials into $\mathrm{Fe}_{2} \mathrm{O}_{3}$ forming composites [24]. A good number of literature is available 
wherein a thermodynamically stable form of iron oxide, $\alpha-\mathrm{Fe}_{2} \mathrm{O}_{3}$ (Hematite), coupled with carbon nano fiber via methods like hydrothermal [25,26,27], electrospinning [28,29], vapour growth [30], gel templating [31] and mechanical press [32] has been utilized as efficient negative electrode in $\mathrm{Li}$ ion/ $\mathrm{Na}$ ion batteries and or as supercapacitor in the potential range from -1.2 to $0 \mathrm{~V}$. There are some reports where $\alpha-\mathrm{Fe}_{2} \mathrm{O}_{3}$ hybrid materials is utilised as positive electrode in aqueous electrolytes [33,34]. In all the cases, electrode material fabrication methods have involved the use of toxic, expensive chemicals and complicated chemical and physical treatments that can lead to environmental implications with cost. There are only two reports available in literature on the greener synthesis of $\alpha-\mathrm{Fe}_{2} \mathrm{O}_{3}$, wherein $\alpha-\mathrm{Fe}_{2} \mathrm{O}_{3}$ was obtained by chemical and physical treatments on up-cycled industrial mill scale waste [35] and in another case, annealing of a mixture of iron hydroxide and dextran chemicals at various temperatures [36]. However, to the best of our knowledge, there are no reports on the use of rust derived nano $\alpha-\mathrm{Fe}_{2} \mathrm{O}_{3}$ for application as hybrid supercapacitor. The rusting process called corrosion is a weathering phenomenon capable of giving aggregates of nano scaled iron oxide, a rust product [37].

In the present paper, we propose a scalable, simple, smart strategy to evolve nano-scaled $\alpha$ $\mathrm{Fe}_{2} \mathrm{O}_{3}$ with an aim to recycle huge pure iron rust waste available. The method is truly greener, cost effective and requires no chemicals and other expensive treatments. The as synthesised $\alpha-$ $\mathrm{Fe}_{2} \mathrm{O}_{3}$ was further coupled with CNF and PANI to get binary positive electrode material.

\section{Experimental details}

\subsection{Extraction of nano- $\alpha-\mathrm{Fe}_{2} \mathrm{O}_{3}$ from iron rust}

The iron rust from moderately rusted pure iron pipes/ iron bars was hand peeled and collected. The collected iron rust was grinded for a couple of hours, washed with deionised water for several times, dried naturally and annealed at $550{ }^{\circ} \mathrm{C}$ for 5 hours. After the heat treatment, the collected powder was further grinded to fine powder for an hour and again annealed for an hour at $550{ }^{\circ} \mathrm{C}$. Finally, it is cooled and subjected to characterization.

\subsection{Fabrication of carbon nanofibers (CNF)}

For CNF preparation, the solution used for electrospinning was prepared by dissolving 10 wt \% of polyacrylonitrile (PAN, Sigma Aldrich) in Dimethylformamide (DMF, Sigma Aldrich with a constant magnetic stirring for 2 hours at $70^{\circ} \mathrm{C}$. The solution was loaded into 10 $\mathrm{ml}$ syringe for electrospinning, the distance between needle tip of syringe and fibers collector 
plate was maintained at $15 \mathrm{~cm}$, the injecting solution flow rate was kept at $0.8 \mathrm{ml} / \mathrm{h}$. The applied voltage between metallic syringe and collector plate was $20 \mathrm{kV}$. The as-prepared electro spun PAN fibers were further transferred to horizontal tube furnace for carbonization process. In this process, initially the PAN fibers were stabilized at $220{ }^{\circ} \mathrm{C}$ for one hour and then the carbonization was carried out at $600{ }^{\circ} \mathrm{C}$ in nitrogen atmosphere for further one hour, finally the temperature was reduced to $400{ }^{\circ} \mathrm{C}$ to activate $\mathrm{CNF}$ for another one hour. After natural cooling, the fibers were collected and stored in a dry desiccator.

\subsection{Preparation of $\alpha-\mathrm{Fe}_{2} \mathrm{O}_{3} / \mathrm{CNF}$ composite by hydrothermal}

For hydrothermal process, the CNF was mixed in deionised water and sonicated for 3 hours to get uniform dispersion. To this, $\alpha-\mathrm{Fe}_{2} \mathrm{O}_{3}$ was added and mixed under magnetic stirring for an hour. In order to get heavy decoration, the weight ratio of CNF and $\alpha-\mathrm{Fe}_{2} \mathrm{O}_{3}$ was taken in 1:2 proportions. This mixture was subsequently transferred into a Teflon coated stainless steel autoclave for 8 hours at $140^{\circ} \mathrm{C}$. Finally, after natural cooling of autoclave, the content was removed, washed centrifugally and the final product was dried at $70{ }^{\circ} \mathrm{C}$ overnight to obtain $\alpha$ $\mathrm{Fe}_{2} \mathrm{O}_{3} / \mathrm{CNF}$.

\subsection{Preparation of $\alpha-\mathrm{Fe}_{2} \mathrm{O}_{3} / \mathrm{PANI}$ composite}

A mixture of $25 \mathrm{ml}$ of $1 \mathrm{M} \mathrm{HCl}$ (Sigma Aldrich) solution and $5 \mathrm{ml}$ 0.25M APS (Ammonium peroxy disulphate, E Merk), after magnetic stirring for an hour, was filled in a burette. A $25 \mathrm{ml}$ of $1 \mathrm{M} \mathrm{HCl}$ and $5 \mathrm{ml} 0.25 \mathrm{M}$ aniline (Sigma Aldrich), taken in a beaker was stirred magnetically for 30 minutes, to this $50 \mathrm{mg}$ of $\alpha-\mathrm{Fe}_{2} \mathrm{O}_{3}$ was added and sonicated for 30 minutes. It is then transferred to an ice bath. To this, APS solution was added dropwise from a burette. After polymerization, solution was centrifugally washed several times with water and dried at $80{ }^{\circ} \mathrm{C}$ in vacuum oven.

\subsection{Electrode preparation method}

For electrochemical testing, Graphite rod coated with a slurry, prepared by mixing $\alpha$ $\mathrm{Fe}_{2} \mathrm{O}_{3} / \mathrm{CNF}$ or PANI: Poly Vinylidene Difluoride (PVDF): Carbon black taken in 85:10:5 ratio was used as electrodes. After dip coating, the carbon rod was removed and dried at $80^{\circ} \mathrm{C}$ in an oven. The PVDF was used as a binder while carbon black to maintain electrical conductivity.

\subsection{Materials Characterization}

X-ray diffraction (XRD) of $\alpha-\mathrm{Fe}_{2} \mathrm{O}_{3}, \mathrm{CNF}$ and $\alpha-\mathrm{Fe}_{2} \mathrm{O}_{3} / \mathrm{CNF}, \alpha-\mathrm{Fe}_{2} \mathrm{O}_{3} / \mathrm{PANI}$ composites were performed on Rigaku D/MAX-RB X-ray diffractometer with $\mathrm{Cu}-\mathrm{K} \alpha$ radiation at scan rate 
$1 \%$ min. The surface morphology and compositional analysis of CNF, $\alpha-\mathrm{Fe}_{2} \mathrm{O}_{3}, \alpha-\mathrm{Fe}_{2} \mathrm{O}_{3} / \mathrm{CNF}$ and $\alpha-\mathrm{Fe}_{2} \mathrm{O}_{3} / \mathrm{PANI}$ composites were investigated using Scanning Electron Microscope (Carl Zeiss EVO-18) equipped with energy dispersive X-ray spectroscopy (EDAX). The detailed morphology, microstructures and crystalline nature of $\alpha-\mathrm{Fe}_{2} \mathrm{O}_{3}$ was further investigated using Transmission Electron Microscopy (TEM), High Resolution Transmission Electron Microscope (HRTEM) and Selected Area Electron Diffraction (SAED) were performed on TEM (JEOL 3010) and HRTEM (Tecnai G2, F30). The electrochemical performances of composite electrodes were measured on AutoLab electrochemical workstation (PGSTAT204) using three electrode system at room temperature in $1 \mathrm{M} \mathrm{H}_{2} \mathrm{SO}_{4}$ electrolyte. For cyclic voltammetry, $\alpha-\mathrm{Fe}_{2} \mathrm{O}_{3} / \mathrm{CNF}$ and $\alpha-\mathrm{Fe}_{2} \mathrm{O}_{3} / \mathrm{PANI}$ composites coated on graphite rods were used as working electrode, platinum wire as counter electrode and calomel as the reference electrode. The electrochemical measurements were performed at scan rate $5-100 \mathrm{mV} / \mathrm{s}$ in a potential range of $0-1 \mathrm{~V}$. The capacitance of the electrode was galvano-statically measured in the potential range of $0-1 \mathrm{~V}$ at current density of 1-10 $\mathrm{A} \mathrm{g}^{-1}$. Electrochemical impedance spectroscopy was performed under open circuit potential with frequency ranging from $10^{-2}$ to $10^{5} \mathrm{~Hz}$.

\section{Results and discussion}

\subsection{Evolution of nano $\alpha-\mathrm{Fe}_{2} \mathrm{O}_{3}$}

In order to understand feasibility of formation of rust in to nanosized $\mathrm{Fe}_{2} \mathrm{O}_{3}$, we look into the theory of corrosion and role of mechanical grinding and annealing. The rust formation process, under ambient environment in presence of water and oxygen involves formation of local electrochemical/ concentration cells on the surface of iron structures, with formation of cathodes and anodes. The products of reactions at cathode and anode are $\mathrm{Fe}^{+2}$ and $\mathrm{OH}^{-}$ions respectively, migrates toward each other and meet in between to form molecular, hydrous $\mathrm{Fe}(\mathrm{OH})_{2}, \mathrm{FeOOH}$ as initial products of corrosion. These molecular particles grow further via combinations of $\mathrm{Fe}^{+2}$ and $\mathrm{OH}^{-}$ions to get clusters, where nanosized particles are loosely held together via weak Vander-Waals and Hydrogen bondings [37,38]. The corrosion product is porous, so that corrosion continues further till access of environmental water and oxygen is present that follows exponential decay. The natural ageing and drying converts $\operatorname{Fe}(\mathrm{OH})_{2}$ and $\mathrm{FeOOH}$ to $\mathrm{FeO} \times \mathrm{xH}_{2} \mathrm{O}$ and $\mathrm{Fe}_{2} \mathrm{O}_{3}$ clusters. Thus, simple annealing is sufficient to evaporate coordinated water molecules from remaining $\mathrm{FeOOH}, \mathrm{FeO} \times \mathrm{xH}_{2} \mathrm{O}$ to form $\mathrm{Fe}_{2} \mathrm{O}_{3}$, while strong mechanical grinding could break loosely held cluster to nanoscale range $\mathrm{Fe}_{2} \mathrm{O}_{3}$ particles. It is 
to be noted that the usual chemical formation is a precipitation process that involves nucleation, growth and termination steps, that usually results into hard grains and clusters.

\subsection{X-ray diffraction (XRD)}

XRD patterns of as-obtained $\alpha-\mathrm{Fe}_{2} \mathrm{O}_{3}, \mathrm{CNF}, \alpha-\mathrm{Fe}_{2} \mathrm{O}_{3} / \mathrm{CNF}$ and $\alpha-\mathrm{Fe}_{2} \mathrm{O}_{3} / \mathrm{PANI}$ are shown in Fig. 1. XRD pattern of as prepared $\alpha-\mathrm{Fe}_{2} \mathrm{O}_{3}$ shows presence of sharp diffraction lines matching exactly with the pattern displayed in JCPDS card No. 33-0664, confirming the presence of only Rhombohedral modification of $\alpha-\mathrm{Fe}_{2} \mathrm{O}_{3}$. The presence of sharp diffraction lines indicates good crystallinity of $\alpha-\mathrm{Fe}_{2} \mathrm{O}_{3}$ sample. The diffraction peaks at $2 \theta$ values of $24.10,33.20,35.60$, $40.90,49.50,54.10,57.60,62.40$ and 64.00 degree have been assigned to the reflections originating from (012), (104), (110), (113), (024), (116), (018), (214), (300) planes of $\alpha-\mathrm{Fe}_{2} \mathrm{O}_{3}$ respectively [12].

The average crystallite size of the as prepared $\mathrm{Fe}_{2} \mathrm{O}_{3}$ nanoparticles was about $28 \mathrm{~nm}$, calculated from the Debye- Scherrer equation based on the measurements of the FWHM of the strongest (110) peaks No diffraction peaks due to unknown impurities/contaminant have been observed indicating high purity of sample. XRD patterns of CNF displays a characteristic broad peak due to (111) plane of carbon material corresponding to interlayer packing of hexagonal carbon sheets. When $\alpha-\mathrm{Fe}_{2} \mathrm{O}_{3}$ is coupled with $\mathrm{CNF}$, the crystal phase of $\alpha-\mathrm{Fe}_{2} \mathrm{O}_{3}$ did not changes and the diffraction peak at (111) of carbon also present in the XRD pattern of $\alpha$ $\mathrm{Fe}_{2} \mathrm{O}_{3} / \mathrm{CNF}$. Thus, the composite $\alpha-\mathrm{Fe}_{2} \mathrm{O}_{3} / \mathrm{CNF}$ keep the characteristics of peak pattern of both of the material with the diminishing intensity of (111) peak of the carbon material due to introduction of $\alpha-\mathrm{Fe}_{2} \mathrm{O}_{3}$ nanoparticles. Similar observations are indicated by $\alpha-\mathrm{Fe}_{2} \mathrm{O}_{3} / \mathrm{PANI}$ composite. It displays prominent peak corresponding to Polyaniline (Emeraldine hydrochloride, JCPDS No 49-2500) and those corresponding to $\alpha-\mathrm{Fe}_{2} \mathrm{O}_{3}$. 


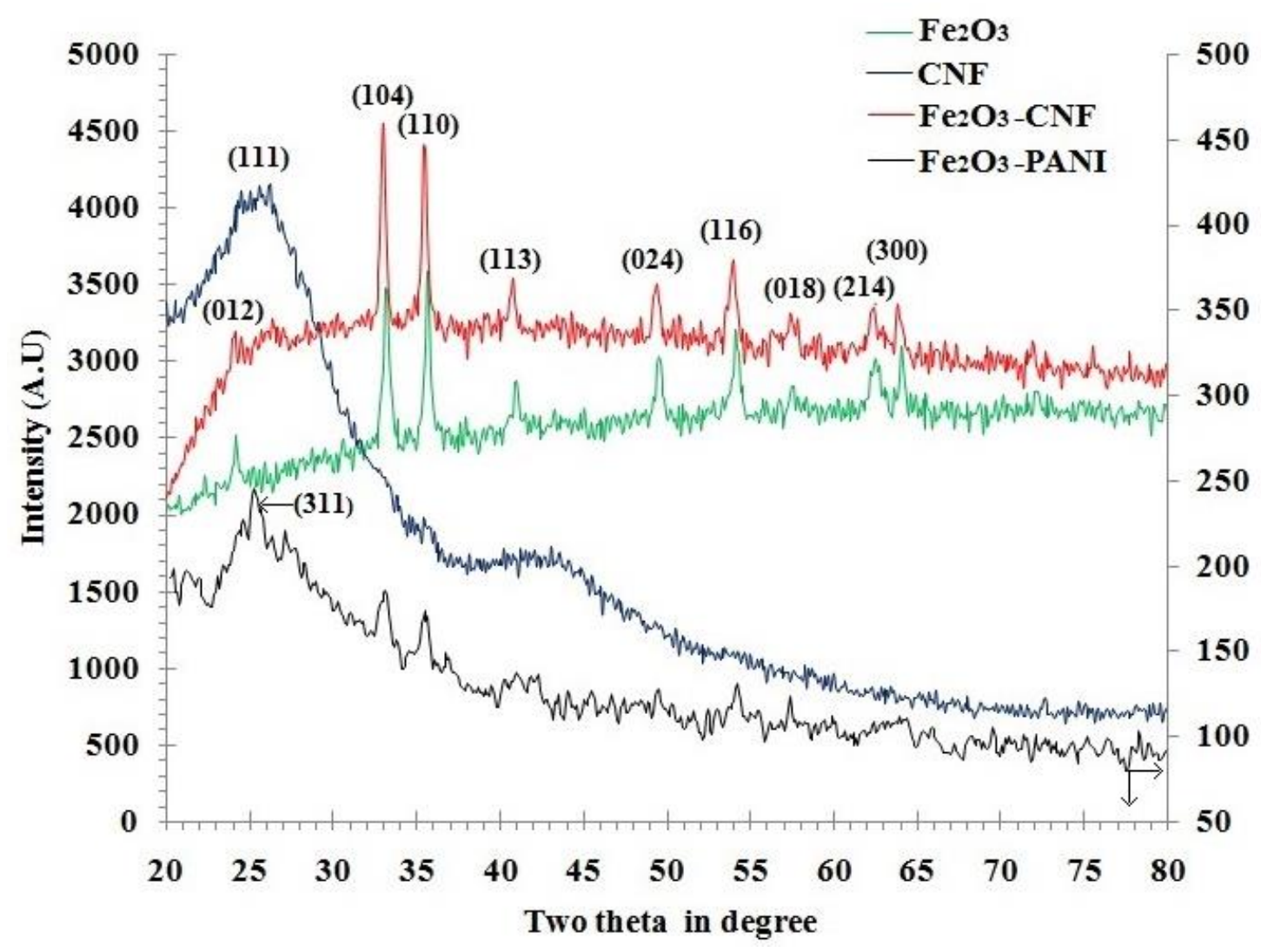

Figure 1: XRD patterns of $\alpha-\mathrm{Fe}_{2} \mathrm{O}_{3}$, Carbon fibers, $\alpha-\mathrm{Fe}_{2} \mathrm{O}_{3} / \mathrm{CNF}$ and $\alpha-\mathrm{Fe}_{2} \mathrm{O}_{3} / \mathrm{PANI}$ composites.

\section{Scanning electron microscopy (SEM) and energy dispersive X-ray spectroscopy (EDX)}

The SEM image of CNF, $\alpha-\mathrm{Fe}_{2} \mathrm{O}_{3}, \alpha-\mathrm{Fe}_{2} \mathrm{O}_{3} / \mathrm{CNF}$ and $\alpha-\mathrm{Fe}_{2} \mathrm{O}_{3} / \mathrm{PANI}$ are shown in Fig. 2(ad) respectively, Fig. 2(e,f) displays EDAX of $\alpha-\mathrm{Fe}_{2} \mathrm{O}_{3} /$ PANI and $\alpha-\mathrm{Fe}_{2} \mathrm{O}_{3} / \mathrm{CNF}$ respectively. The morphology of CNF exhibits continuous network type of fibers with average diameter of 300-350 nm (Fig 2a). The CNF fiber was able to maintain its long and continuous structure even after carbonisation giving large aspect ratio with moderate interconnectivity among the fibers. Such type of structure is desirable as it provides transportation directionality with short ionic length during charge storage [18]. Fig $2 b$ shows the SEM image of as prepared $\alpha-\mathrm{Fe}_{2} \mathrm{O}_{3}$, displaying nano-cluster, made up of large number of interconnected $\alpha-\mathrm{Fe}_{2} \mathrm{O}_{3}$ nanoparticles having somewhat irregular shapes. The SEM image of $\alpha-\mathrm{Fe}_{2} \mathrm{O}_{3} / \mathrm{CNF}$ composite (Fig 2c) shows quite heavy decoration of $\alpha-\mathrm{Fe}_{2} \mathrm{O}_{3}$ particles over carbon fibers with some segregated $\alpha-\mathrm{Fe}_{2} \mathrm{O}_{3}$ nano particles forming tiny plate-like clusters. The SEM of $\alpha-\mathrm{Fe}_{2} \mathrm{O}_{3} / \mathrm{PANI}$ (Fig.2d) displays quite uniform dispersion of $\alpha-\mathrm{Fe}_{2} \mathrm{O}_{3}$ over PANI fibers. The intimate and heavy junction between $\alpha-\mathrm{Fe}_{2} \mathrm{O}_{3}$ and conducting CNF/PANI is essential for a fast redox reaction during the electrochemical process. The EDAX pattern of $\alpha-\mathrm{Fe}_{2} \mathrm{O}_{3} / \mathrm{CNF}$ displayed in Fig. $2 \mathrm{f}$ confirm the 
presence of carbon, iron and oxygen with no other elemental impurities whereas that of $\alpha$ $\mathrm{Fe}_{2} \mathrm{O}_{3} / \mathrm{PANI}$ (Fig.2e) displays presence of nitrogen in addition to carbon, iron and oxygen without impurities.

a)

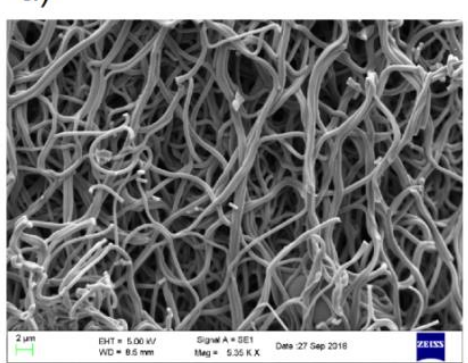

d)
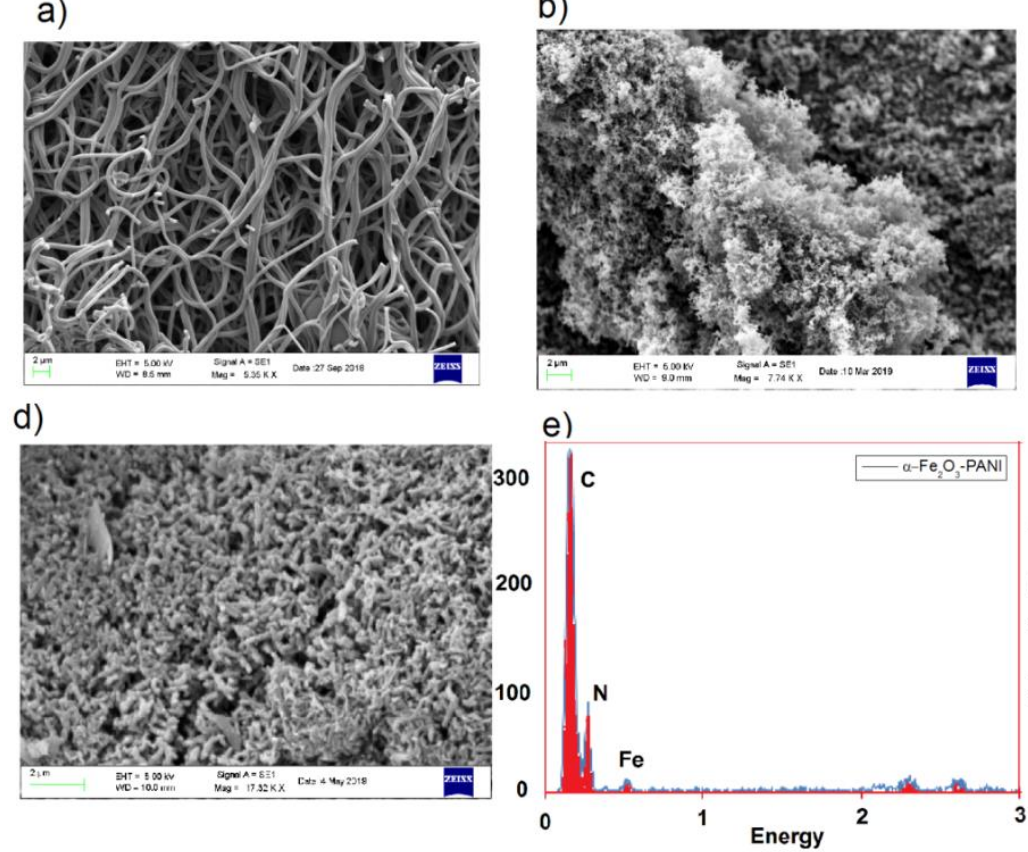

b)

c)

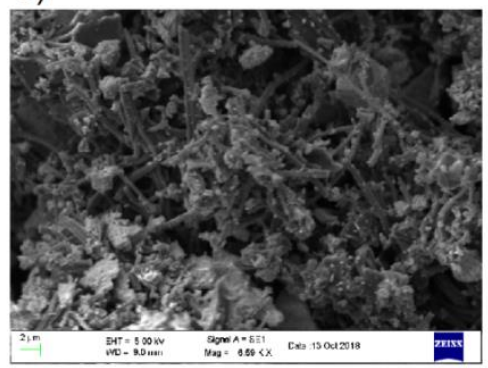

f)

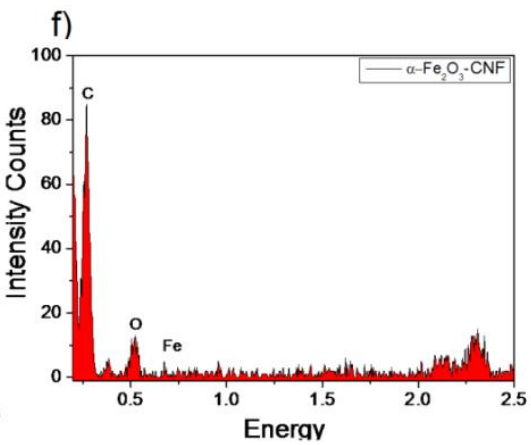

Figure 2: $\mathrm{SEM}$ images of $\mathrm{CNF}(\mathrm{a}), \alpha-\mathrm{Fe}_{2} \mathrm{O}_{3}(\mathrm{~b}), \alpha-\mathrm{Fe}_{2} \mathrm{O}_{3} / \mathrm{CNF}$ (c), $\alpha-\mathrm{Fe}_{2} \mathrm{O}_{3} / \mathrm{PANI}$ (d), EDX spectrum of $\alpha-\mathrm{Fe}_{2} \mathrm{O}_{3} /$ PANI (e) and $\alpha-\mathrm{Fe}_{2} \mathrm{O}_{3} / \mathrm{CNF}$ (f)

\subsection{TEM, HRTEM and SAED of $\alpha-\mathrm{Fe}_{2} \mathrm{O}_{3}$}

The detailed morphology and microstructure of as prepared iron rust have been further investigated by TEM and HRTEM. Figure $3(\mathrm{a}, \mathrm{b})$ shows TEM images of as prepared iron rust at different resolutions, it can be seen that the iron rust is made up of aggregations of numbers of nanoparticles with size ranging from 20 to $50 \mathrm{~nm}$, further the interplanar distance measured out in HRTEM image of $0.25 \mathrm{~nm}$ (Fig 3c) can be indexed to the lattice fringes of $\alpha-\mathrm{Fe}_{2} \mathrm{O}_{3}(110)$ planes, which is a prominently consistent with the results of XRD. Figure 3d shows the SAED pattern of $\alpha-\mathrm{Fe}_{2} \mathrm{O}_{3} \mathrm{NP}$ 's with bright spots in the diffraction circles confirming the crystalline nature of $\alpha-\mathrm{Fe}_{2} \mathrm{O}_{3}$ nanoparticles. 
a)

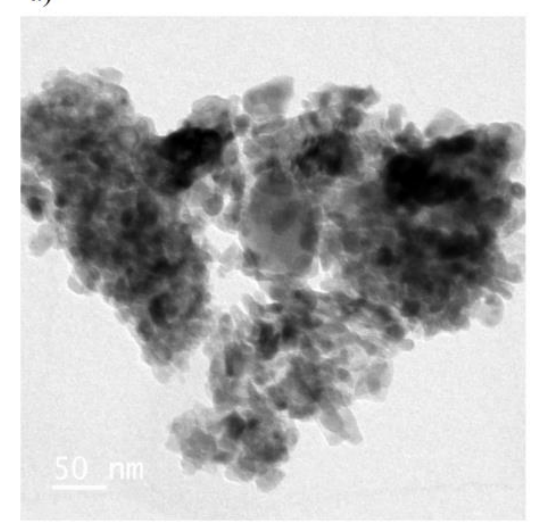

c)

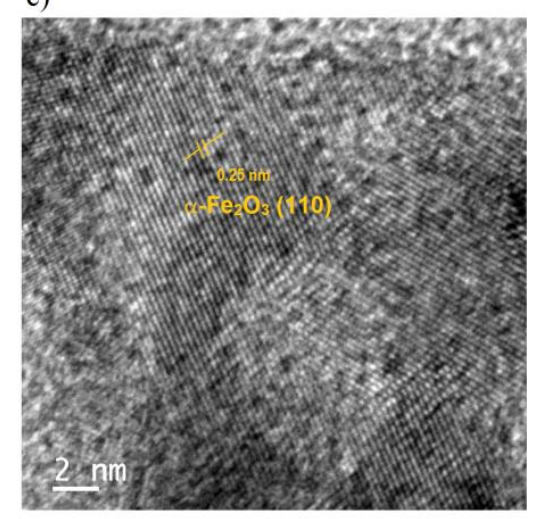

b)

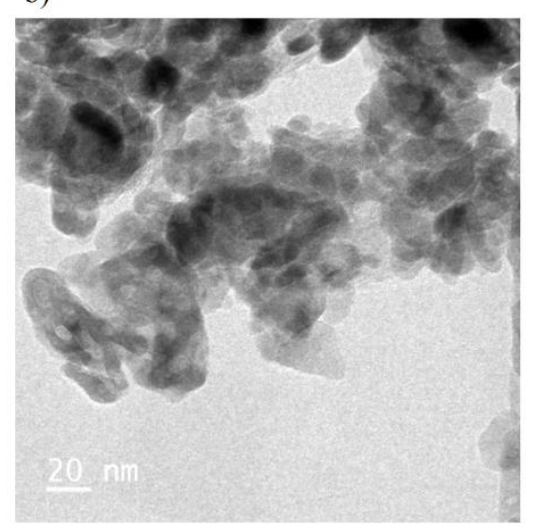

d)

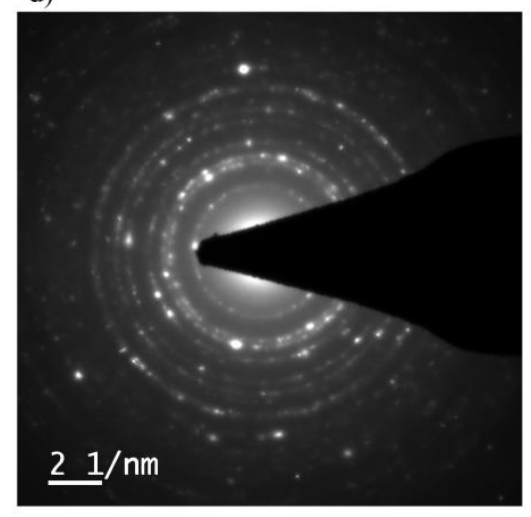

Figure 3(a-d): TEM images of $\alpha-\mathrm{Fe}_{2} \mathrm{O}_{3}(\mathrm{a}, \mathrm{b})$, HRTEM image of $\alpha-\mathrm{Fe}_{2} \mathrm{O}_{3}, \mathrm{SAED}$ pattern of $\alpha-\mathrm{Fe}_{2} \mathrm{O}_{3}(\mathrm{~d})$.

\subsection{Electrochemical performance of $\alpha-\mathrm{Fe}_{2} \mathrm{O}_{3} / \mathrm{CNF}$}

The electrochemical measurements were performed in $1 \mathrm{M} \mathrm{H}_{2} \mathrm{SO}_{4}$ electrolyte in a threeelectrode cell configuration with platinum rod (counter electrode), saturated calomel electrode (reference electrode) and individual working electrodes consisting of $\alpha-\mathrm{Fe}_{2} \mathrm{O}_{3} / \mathrm{CNF}$ and $\alpha-$ $\mathrm{Fe}_{2} \mathrm{O}_{3} / \mathrm{PANI}$ composites deposited on carbon rod. The potential window was kept between 0 1V. Figure 4(a,c) displays CV profile before cycling, whereas, fig (b,d) displays CV profile after 5000 cycles for $\alpha-\mathrm{Fe}_{2} \mathrm{O}_{3} / \mathrm{CNF}$ and $\alpha-\mathrm{Fe}_{2} \mathrm{O}_{3} / \mathrm{PANI}$ at 5,10,20,30,40,50,75 and $100 \mathrm{mV} / \mathrm{s}$ scan rates respectively.

The approximately symmetrical, rectangular appearance of the CV profile with distinct redox peaks demonstrates the pseudo-capacitive behaviour. A couple of well-defined redox peaks can be found within $0.2-0.8 \mathrm{~V}$ due to faradic redox reactions corresponding to the reversible conversions between $\mathrm{Fe}^{3+}$ and $\mathrm{Fe}^{2+}$ [20]. The $\alpha-\mathrm{Fe}_{2} \mathrm{O}_{3} / \mathrm{PANI}$ exhibited much larger captive current (180 mA) (Fig 4c) than $\mathrm{Fe}_{2} \mathrm{O}_{3} / \mathrm{CNF}\left(3 \mathrm{~mA}\right.$ ) (Fig 4a) as against bare $\alpha-\mathrm{Fe}_{2} \mathrm{O}_{3}$, which did not show any comparable current. The highest electrochemical performance of $\alpha-$ 
$\mathrm{Fe}_{2} \mathrm{O}_{3} / \mathrm{PANI}$ has been resulted from the well -designed nano-structure, excellent interconnectivity among PANI fibers and the synergistic effect between the two-components.

The nanosized $\alpha-\mathrm{Fe}_{2} \mathrm{O}_{3}$ particles provide fast faradic process resulting in high pseudocapacitance contributing to much higher specific capacitance. It is evident that with the increase in the sweep rate, the peak current notably increases keeping the CV profiles intact. A slight potential shift of the redox peaks can be ascribed to the internal charge transfer resistance [39]. With the increase of scan rate, the specific capacitance was found to diminish gradually as usual and considered as normal behaviour due to faster diffusion of ions at lower scan rate than higher [40]. After 5000 cycling (Fig.4 b,d), the area under the curve has decreased for $\alpha$ $\mathrm{Fe}_{2} \mathrm{O}_{3} / \mathrm{CNF}$ and $\alpha-\mathrm{Fe}_{2} \mathrm{O}_{3} / \mathrm{PANI}$ electrodes indicating decrease in specific capacitance of both materials.
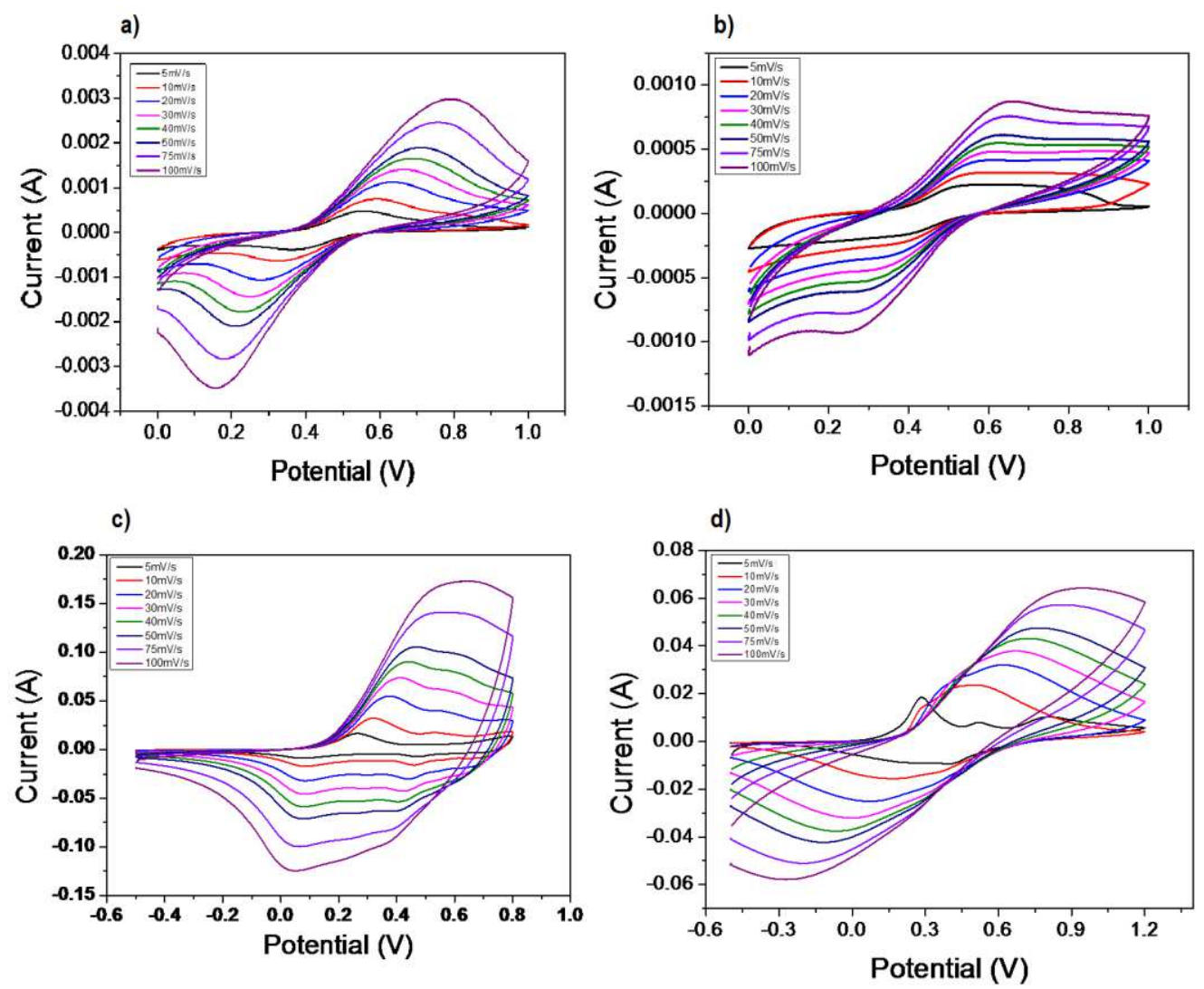

Figure 4: Cyclic voltammetry at different scan rates for CNF-Fe $\mathrm{O}_{3}$ in $1 \mathrm{M} \mathrm{H}_{2} \mathrm{SO}_{4}$ before cycling (a) and after 5000 cycling (b) and for PANI-Fe $\mathrm{O}_{3}$ in $1 \mathrm{M} \mathrm{H}_{2} \mathrm{SO}_{4}$ before cycling (c) and after cycling and (d)

Figure 5(a,b) show Nyquist plot of $\alpha-\mathrm{Fe}_{2} \mathrm{O}_{3} / \mathrm{CNF}$ and $\alpha-\mathrm{Fe}_{2} \mathrm{O}_{3} / \mathrm{PANI}$ within the frequency range of 0.01 to $10^{5} \mathrm{~Hz}$ at open circuit potential before (black data) and after 5000 cycles (red 
data) respectively. As can be seen from EIS spectra, $\alpha-\mathrm{Fe}_{2} \mathrm{O}_{3} / \mathrm{CNF}$ exhibits one depressed semicircle (Fig.5a) in the high frequency range (due to charge transfer process, Rct) and a sloped straight line in the low frequency region (due to diffused limited process, W). The absence of a linear portion in low frequency range before and after cycling indicates presence of negligible surface Warburg resistance in the electrolyte due to poor conductivity of $\alpha-\mathrm{Fe}_{2} \mathrm{O}_{3}$ so that the charge transfer resistance becomes high to make electrochemical reaction too slow to enable diffusion process not a rate control step, therefore, the Warburg impedance become insignificant thus the straight-line portion at the low frequency range is not obvious anymore [1].
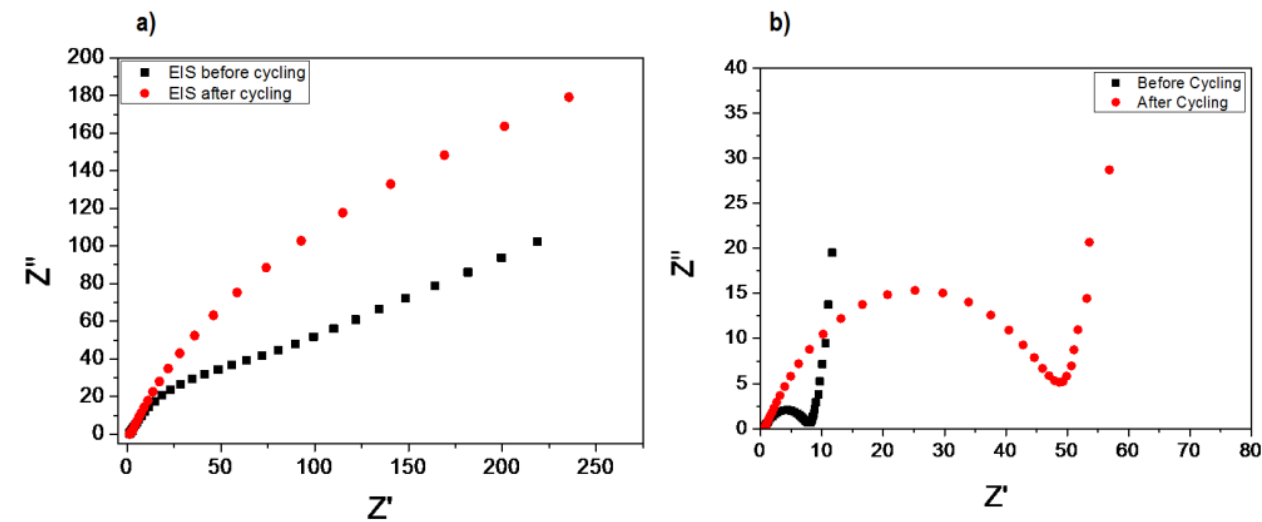

c)

d)
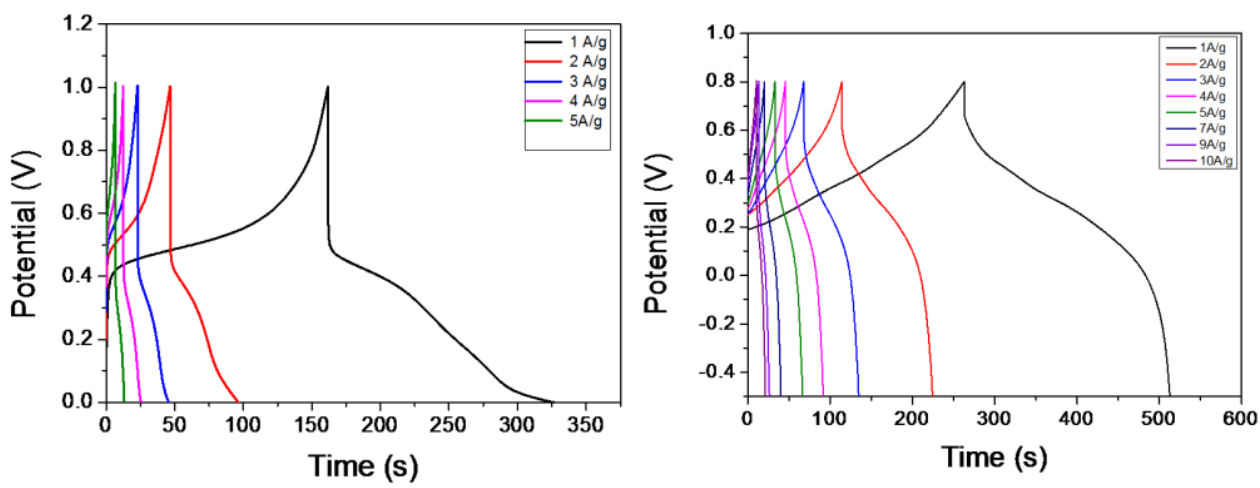

Figure 5: Cyclic voltammetry curves measured at different scan rates for $\mathrm{PANI}-\mathrm{Fe}_{2} \mathrm{O}_{3}$ in $1 \mathrm{M}$ $\mathrm{H}_{2} \mathrm{SO}_{4}$ (a) before cycling and (b) after 5000 cycling; (c) EIS before and after cycling and (d) Galvanostatic charge-discharge curves at different current densities

On the other hand, the Faradic interfacial charge-transfer resistance rises slowly with cycling (red data) ascribing to the fact that the partial deformation/ destruction of nanostructure and the corrosion of the current collector was occurred during the redox reaction, yielding low conductivity after cyclings [20]. The notable reduction in semicircle diameter for $\alpha$ $\mathrm{Fe}_{2} \mathrm{O}_{3} / \mathrm{PANI}$ (Fig 5 b, black data) than $\alpha-\mathrm{Fe}_{2} \mathrm{O}_{3} / \mathrm{CNF}$ display outstanding electrical conductivity 
of $\alpha-\mathrm{Fe}_{2} \mathrm{O}_{3} / \mathrm{PANI}$, contributing much superior electrochemical performance. A straight line versus a high angle to the $Z$ ' axis before and after cycling have been noticed, suggesting coexistence of abundant ions diffusion path-ways and their rapid movement in the active materials leading to differential capacitance $[22,40]$.

Figure 5(c,d) shows GCD curves of $\alpha-\mathrm{Fe}_{2} \mathrm{O}_{3} / \mathrm{CNF}$ and $\alpha-\mathrm{Fe}_{2} \mathrm{O}_{3} / \mathrm{PANI}$ recorded at different current density respectively. A presence of a perfect triangular shaped charge/discharge curves implies presence of pure EDLC type capacitance, however, the GCD curves of both the electrodes shows a plateau at about $0.3-0.4 \mathrm{~V}$ along with triangle indicating the presence of pseudo-capacitive faradic feature in addition. As displayed in Fig 5(c,d), $\alpha-\mathrm{Fe}_{2} \mathrm{O}_{3} / \mathrm{PANI}$ exhibited a longer discharge time (520 sec) than $\alpha-\mathrm{Fe}_{2} \mathrm{O}_{3} / \mathrm{CNF}$ composites (330 sec).

Figure 6(a) displays the comparison of $\mathrm{CV}$ of $\alpha-\mathrm{Fe}_{2} \mathrm{O}_{3} / \mathrm{CNF}$ and $\alpha-\mathrm{Fe}_{2} \mathrm{O}_{3} / \mathrm{PANI}$ at $5 \mathrm{mV} / \mathrm{s}$. It clearly shows much larger area for $\alpha$ - $\mathrm{Fe}_{2} \mathrm{O}_{3} / \mathrm{PANI}$ cycle than $\mathrm{Fe}_{2} \mathrm{O}_{3} / \mathrm{CNF}$ indicating high captive nature of $\alpha-\mathrm{Fe}_{2} \mathrm{O}_{3} / \mathrm{PANI}$ than $\mathrm{Fe}_{2} \mathrm{O}_{3} / \mathrm{CNF}$ composites. The specific capacitance of both the composites have been calculated from GCD curves at different current density using equation (1),

$C_{s}=\frac{i \times \Delta t}{m \times \Delta V}$

Where, $\mathrm{C}_{\mathrm{s}}$ is the specific discharge capacitance, $\mathrm{i}$ is the current density, $\Delta \mathrm{t}$ is the discharge time, $\Delta \mathrm{V}$ is the potential during discharge.

Figure 6(b) shows the relationship between the specific capacitance at different current density. The specific capacitance of $\alpha-\mathrm{Fe}_{2} \mathrm{O}_{3} / \mathrm{CNF}$ and $\alpha-\mathrm{Fe}_{2} \mathrm{O}_{3} / \mathrm{PANI}$ composite were 88.88 and $192.29 \mathrm{Fg}^{-1}$ at $1 \mathrm{~A} \mathrm{~g}^{-1}$ current density, was dramatically decreased to $5.43 \mathrm{Fg}^{-1}$ (at current density of $5 \mathrm{~A} \mathrm{~g}^{-1}$ ) for $\alpha-\mathrm{Fe}_{2} \mathrm{O}_{3} / \mathrm{CNF}$ and to $84.04 \mathrm{Fg}^{-1}$ (at current density of $10 \mathrm{~A} \mathrm{~g} \mathrm{~g}^{-1}$ ) respectively. 
(a)

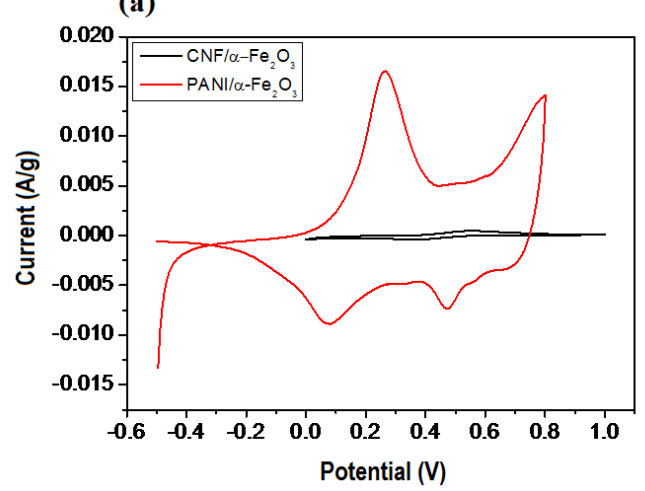

(c)

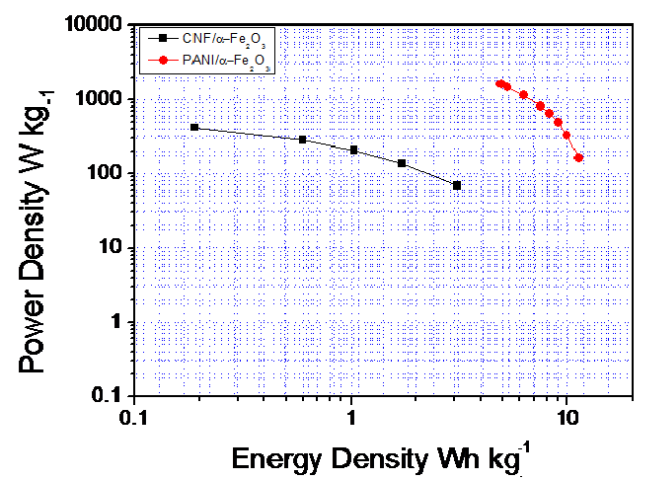

(b)

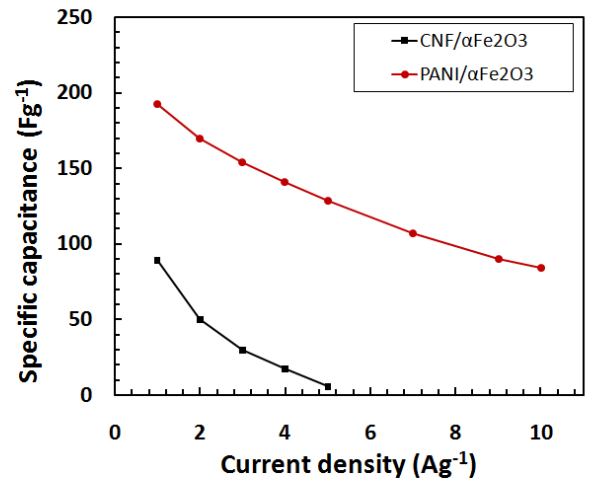

(d)

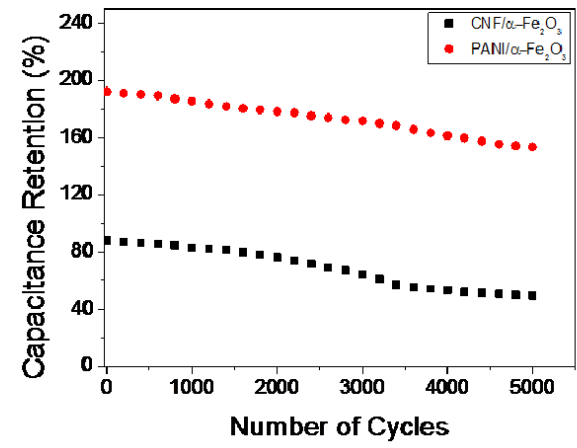

Figure 6: (a) C.V curves for $\alpha-\mathrm{Fe}_{2} \mathrm{O}_{3} / \mathrm{CNF}$ and $\alpha-\mathrm{Fe}_{2} \mathrm{O}_{3} / \mathrm{PANI}$ at $5 \mathrm{mV} / \mathrm{Sec}$; (b) Specific capacitance of $\alpha-\mathrm{Fe}_{2} \mathrm{O}_{3} / \mathrm{CNF}$ and $\alpha-\mathrm{Fe}_{2} \mathrm{O}_{3} / \mathrm{PANI}$ as a function of different current densities; (c) Ragone plot of $\alpha-\mathrm{Fe}_{2} \mathrm{O}_{3} / \mathrm{CNF}$ obtained from Galvanostatic charge-discharge curve at different current densities; (d) Cycling stability of $\alpha-\mathrm{Fe}_{2} \mathrm{O}_{3} / \mathrm{CNF}$ and $\alpha-\mathrm{Fe}_{2} \mathrm{O}_{3} / \mathrm{PANI}$ over 5000 cycles at current density of $1 \mathrm{Ag}^{-1}$

Both of the materials showed the same trend of decreasing specific capacitance with the increments in the discharge current density. The active surface of the electrodes may be probably becoming inapproachable for charge stockpile during the charge-discharge process, resulting in the comparatively inadequate Faradic redox reaction at higher discharge current densities, which accounts for the abatement of specific capacitance [41]. It is to be noted that $\mathrm{Fe}_{2} \mathrm{O}_{3}$ nano spindles, synthesised chemically via hydrothermal route, as positive electrode in $0.5 \mathrm{M} \mathrm{K}_{2} \mathrm{SO}_{4}$ electrolyte showed a specific capacitance of $159 \mathrm{Fg}^{-1}$ at $0.1 \mathrm{~A} \mathrm{~g}^{-1}$ current density [34]. The results are much comparable with mill scale derived $\mathrm{Fe}_{2} \mathrm{O}_{3}$ sprayed on large area current collector electrode (method reported as a greener synthetic route) which gave $92 \mathrm{Fg}^{-1}$ capacitance at $5 \mathrm{mVs}^{-1}$ scan rate with $20 \%$ loss after 5000 cycles [35].

Fig. 5(c) shows the Ragone plot for $\alpha-\mathrm{Fe}_{2} \mathrm{O}_{3} / \mathrm{CNF}$ (black data) and $\alpha-\mathrm{Fe}_{2} \mathrm{O}_{3} / \mathrm{PANI}$ (red data) electrodes. It is seen that for $\alpha-\mathrm{Fe}_{2} \mathrm{O}_{3} / \mathrm{CNF}$, increase in specific power from 69.39 to 410.63 $\mathrm{WhKg}^{-1}$ the specific energy was decreased from 3.08 to $0.1 \mathrm{WhKg}^{-1}$, whereas $\alpha-$ $\mathrm{Fe}_{2} \mathrm{O}_{3} / \mathrm{PANI}$ showed a maximum specific energy of $11.28 \mathrm{WhKg}^{-1}$ at specific power density of 
162.44 $\mathrm{Wkg}^{-1}$ and a maximum power density of $1623.78 \mathrm{Wkg}^{-1}$ at a specific energy of 4.93 $\mathrm{WhKg}^{-1}$ indicating good power characteristics than $\alpha-\mathrm{Fe}_{2} \mathrm{O}_{3} / \mathrm{CNF}$. The higher power output makes the material promising for applications where high-power output as well as high energy capacity is required. The cycling stability is considered as an effective element of supercapacitor for realistic application purpose. Figure 6(d) demonstrates long term cycling properties of the $\alpha-\mathrm{Fe}_{2} \mathrm{O}_{3} / \mathrm{CNF}$ and $\alpha-\mathrm{Fe}_{2} \mathrm{O}_{3} / \mathrm{PANI}$ composite tested by continuous GCD measurements at current density of $1 \mathrm{Ag}^{-1}$ for 5000 cycles. The specific discharge capacitance of $\alpha-\mathrm{Fe}_{2} \mathrm{O}_{3} / \mathrm{CNF}$ and $\mathrm{Fe}_{2} \mathrm{O}_{3} / \mathrm{PANI}$ electrodes drop by $25 \%$ and $20 \%$ of the initial capacitance respectively after 5000 cycles, displaying an excellent cycling performance for both the electrodes. The loss after 5000 cycling is attributed to the stacking and agglomeration of active sites in the process.

\section{Conclusions}

Decorations of $\alpha-\mathrm{Fe}_{2} \mathrm{O}_{3}$ synthesized from its waste iron rust on CNF and PANI were successfully done by using electrospinning and hydrothermal method. The $\alpha-\mathrm{Fe}_{2} \mathrm{O}_{3} / \mathrm{CNF}$ and $\mathrm{Fe}_{2} \mathrm{O}_{3} / \mathrm{PANI}$ positive electrodes showed a maximum specific capacitance of 88.88 and 192.29

$\mathrm{Fg}^{-1}$ at $1 \mathrm{Ag}^{-1}$, energy density of 3.08 and $11.28 \mathrm{Whkg}^{-1}$ with power density of 69.39 and 162.44 $\mathrm{Wkg}^{-1}$ respectively. A loss of $25 \%$ for $\alpha-\mathrm{Fe}_{2} \mathrm{O}_{3} / \mathrm{CNF}$ and $20 \% \mathrm{Fe}_{2} \mathrm{O}_{3} / \mathrm{PANI}$ in specific capacitance after 5000 continuous charge/discharge cycle indicate a highly stable cycling performance. The excellent electrochemical capacitance of the waste derived $\alpha-\mathrm{Fe}_{2} \mathrm{O}_{3} / \mathrm{PANI}$ composite positive electrode makes it prospectively as a promising electrode material for energy storage in sustainable hybrid supercapacitor.

\section{Declarations:-}

Funding: Not Applicable

Conflicts of interest : No conflicts to declare

Availability of data and material : Not applicable

Code availability : Not applicable

Authors' contributions : Equal contributions by all the authors

Ethics approval : Approved by all authors

Consent to participate : Approved by all authors

Consent for publication : Approved by all authors 


\section{Acknowledgements}

The authors gratefully acknowledge Institute of Science, Nagpur and RTMN University, Nagpur for the Instrument facility provided.

\section{Notes and references}

1. P. Xiong, J. Zhu, X. Wang, J. Power Sources 294, 31-50 (2015)

2. E. Azwar, W. Mahari, J. Chuah, D. Vo, N. Ma, W. Lam, S. Lam, Int. J. Hydrog. Energy 43(45), 20811-20821 (2018)

3. J. Libich, J.Maca, J. Vondrak, O. Cech, M. Sedlarikova, J. Energy Storage 17, 224-227 (2018)

4. X Zhao, H Chen, F Kong, Y Zhang, S Wang, S Liu, L Lucia, P Fatehi, H Pang, Chem. Eng. J 364, 226-243 (2019)

5. R. Kate, S. Khalate, R. Deokate, A review, J. Alloys Compd 734, 89-111 (2018)

6. L. Li, G. Xia, W. Yu, K. Lu, A. Zhang, S. Wang, SM\&T 17, e00085 (2018)

7. W. Wang, Q. Hao, W. Lei, X. Xia, X. Wang, J. Power Sources 269, 250-259 (2014)

8. Y. He, L. Wang, D. Jia, Electrochim. Acta 194, 239-245 (2016)

9. J. Patil, S. Mali, A. Kamble, C. Hong, J. Kim, P. Patil, Appl. Surf. Sci. 423, 641-674 (2017)

10. G. Sun, L. Sun, H. Xie, J. Liu. Nanomaterials 6(7), 129 (2016)

11. Q. Liu, J. Zhu, L. Zhang, Y. Qiu, Renew. Sust. Energ. Rev. 81, 1825-1858 (2018)

12. H. Emadi, M. Niasari, A. Sobhani, Adv. Colloid Interface Sci. 246, 52-74 (2017)

13. X. Tian, N. Zhao, Y. Song, K. Wang, D. Xu, X. Li, Q. Guo, L. Liu, Electrochim. Acta $185,40-51(2015)$

14. X.Song, J.Guo, M. Guo, D. Jia Z, Sun, L. Wang, Electrochim. Acta 206, 337-345 (2016)

15. K. Tang, Y. Li, H. Cao, C. Su, Z. Zhang, Y. Zhang, Electrochim. Acta 190, 678-688 (2016)

16. A. Choudhury, J. Kim, K. Yang, D. Yang, Electrochim. Acta 213, 400-407 (2016)

17. M. Zhi, A. Manivannan, F. Meng, N. Wu, J. Power Sources 208, 345-353 (2012)

18. C. Kim, B. Kim, J. Power Sources 274, 512-520 (2015)

19. S. Zhu, X. Zou, Y. Zhou, Y. Zeng, Y. Long, Z. Yuan, Q. Wu, M. Li, Y.Wang, B. Xiang, J. Alloys Compd 775, 63-71 (2019)

20. V. Nithya, N. Arul, J. Power Sources 327, 297-318 (2016) 
21. Y. Dong, L. Xing, F. Hu, A. Umar, X. Wu, Mater. Res. Bull. 107, 391-396 (2018)

22. N. Jabeen, A. Hussain, Q. Xia, S. Sun, J. Zhu, H. Xia, Adv. Mater. 29(32), 1700804 (2017)

23. Q. Xia, M. Xu, H. Xia, J. Xie, ChemNanoMat 2(7), 588-600 (2016)

24. M. Li, H. He, Vacuum 143, 371-379 (2017)

25. Z. Liu, S. Tay, Mater. Lett. 72(1), 74-77 (2012)

26. C. Wu, X. Li, W. Li, B. Li, Y. Wang, Y. Wang, M. Xu, L. Xing, J. Power Sources 251(1), 85-91 (2014)

27. Y. Zhu, S. Cheng, W. Zhou, J. Jia, L. Yang, M. Yao, M. Wang, J. Zhou, P. Wu, M. Liu, ACS Sustain. Chem. Eng. 5 (6), 5067-5074 (2017)

28. L. Ji, O. Toprakci, M. Alcoutlabi, Y. Yao, Y. Li, S.Zhang, B. Guo, Z. Lin, X. Zhang, ACS Appl. Mater. Interfaces 4 (5), 2672-2679 (2012)

29. J. Cho, Y. Hong, Y. Kang, ACS Nano 9 (4), 4026-4035 (2015)

30. M. Wu, Y. Ou, Y. Lin, Electrochim. Acta 55(9), 3240-3244 (2010)

31. P. Luo, Y. Zou, Mater. Lett. 80(1), 121-123 (2012)

32. M. Nasibi, M. Golozar, G. Rashed, Mater. Lett. 85, 40-43 (2012)

33. A. Singh, K. Mandal, J. Appl. Phys. 117, 105101 (2015)

34. L. Zhu, Z. Chang, Y. Wang, B. Chen, Y. Zhu, W. Tang, Y. Wu, J. Mater. Chem. A 3, 22066-22072 (2015)

35. C. Fu, P. Grant, ACS Sustain. Chem. Eng. 3 (11), 2831-2838 (2015)

36. S. Balsubramanian, K. Purushothaman, G. Muralidharan, RSC Adv. 4(9), 4631 (2014)

37. K. Chew, R. Kuwahara, K. Ohno, Phys. Chem. Chem. Phys. 20, 1653-1663 (2018)

38. R. Balasubramaniyam, A. Ramesh Kumar, P. Dillmann, Curr. Sci. 85(11), 1546-1555 (2003)

39. H. Zhang, C. Lu, C. Chen, L. Xie, P. Zhou, Q. Kong, ChemElectroChem 8, 1990-1996 (2017)

40. N. Chaudhari, S. Chaudhary, J. Yu, Energy Materials 7( 11), 3102-3111 (2014)

41. B. Mei, O. Munteshari, J. Lau, B. Dunn, L. Pilon, J. Phys. Chem. C 122, 194-206 (2018)

42. B. Lokhande, R. Ambare, R. Mane, S. Bharadwaj, Curr Appl Phys. 13, 985-989 (2013) 


\section{Figures}

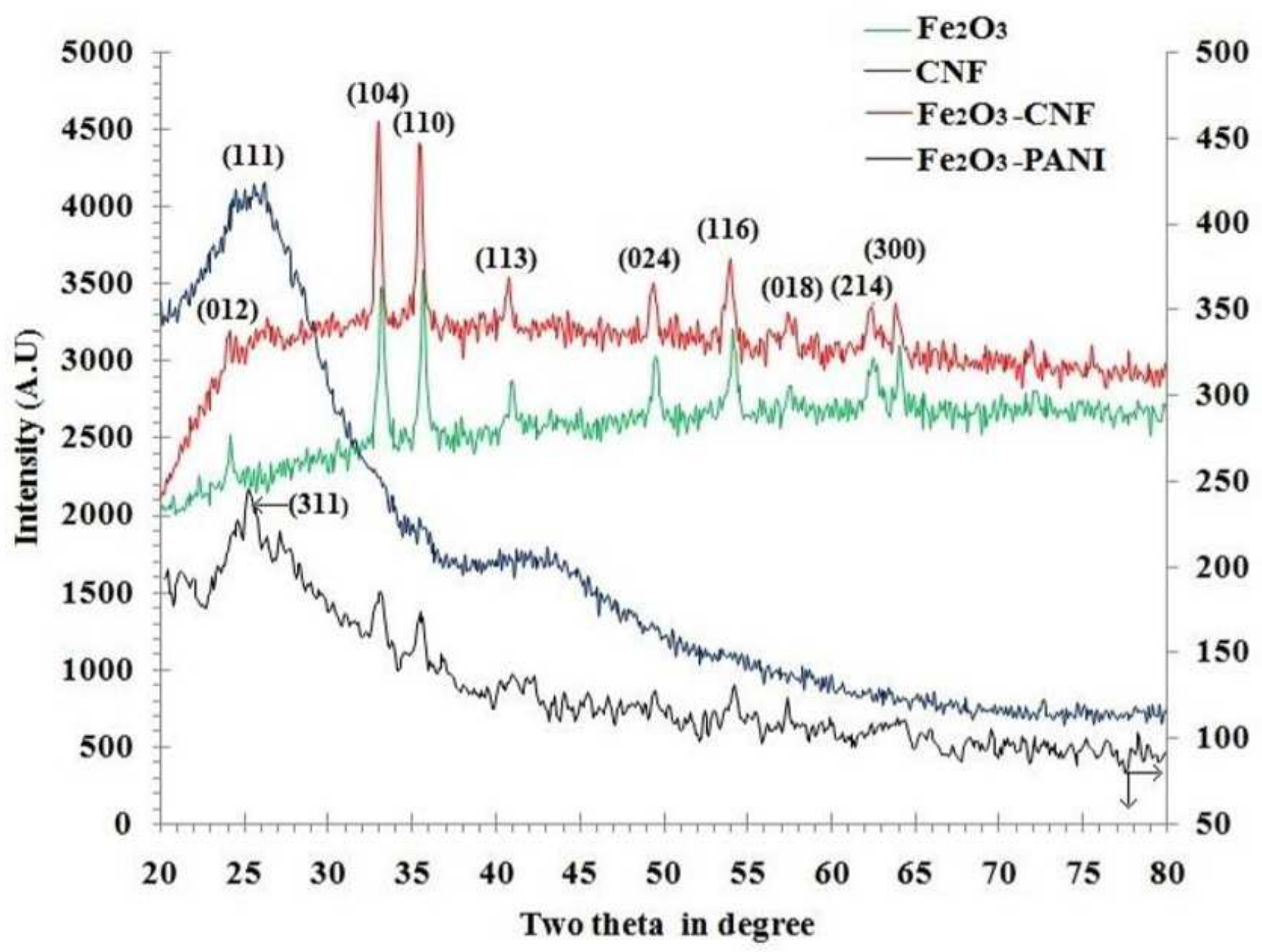

Figure 1

XRD patterns of a-Fe203, Carbon fibers, a-Fe203/CNF and a-Fe2O3/PANI composites. 
a)

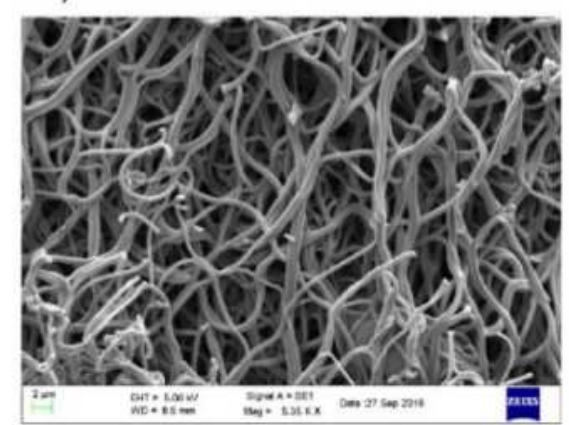

d)

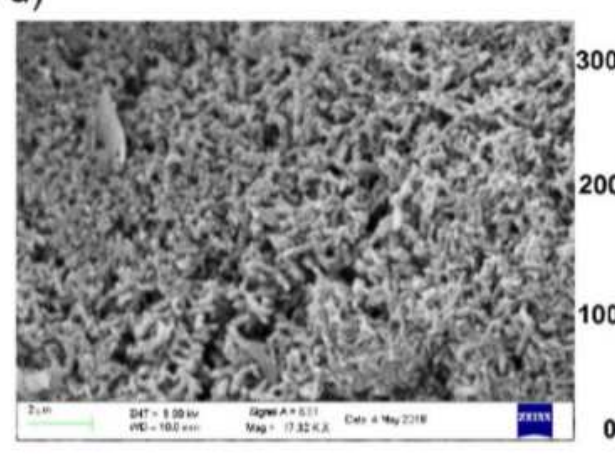

b)

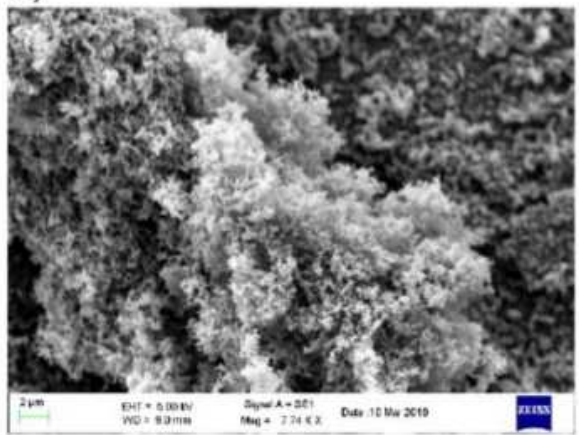

e)

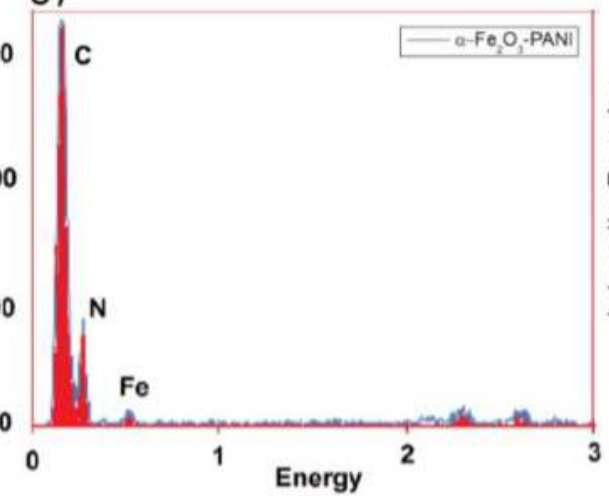

c)
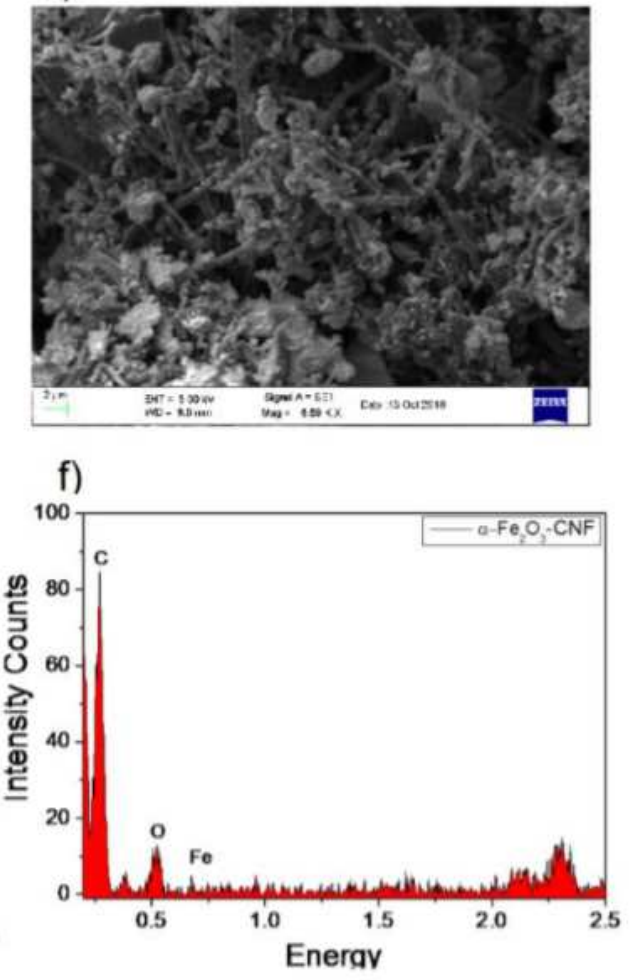

Figure 2

SEM images of CNF(a), a-Fe2O3 (b), a-Fe203/CNF (c), a-Fe203/PANI (d), EDX spectrum of a-Fe203/ PANI (e) and a-Fe2O3/ CNF (f) 
a)

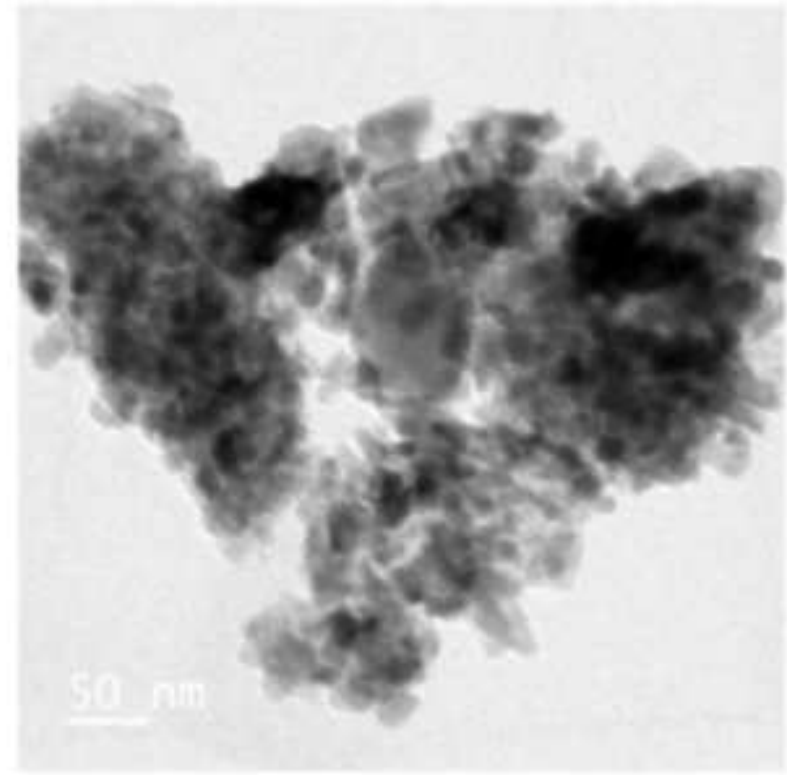

c)

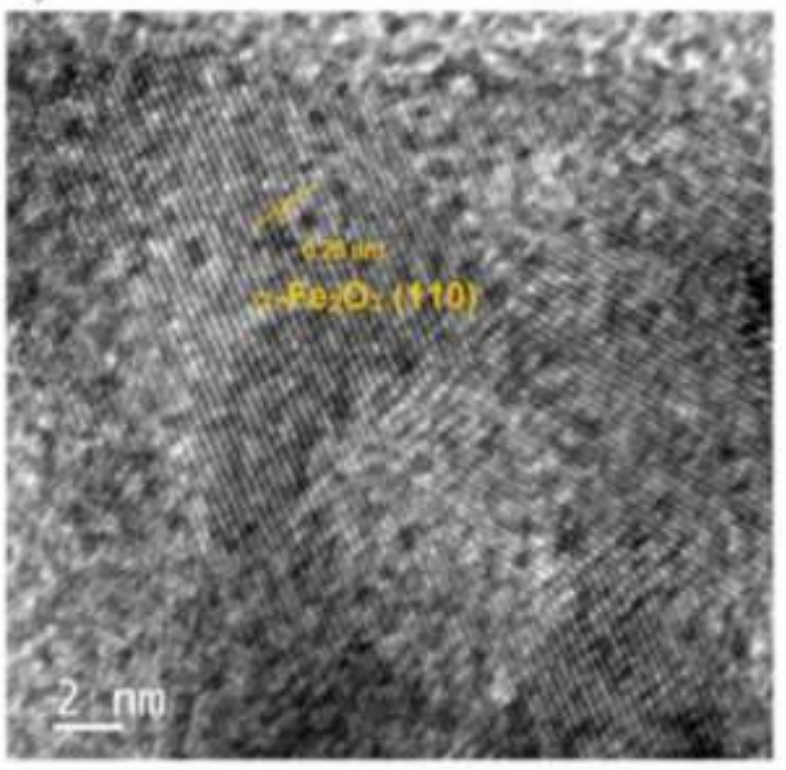

b)

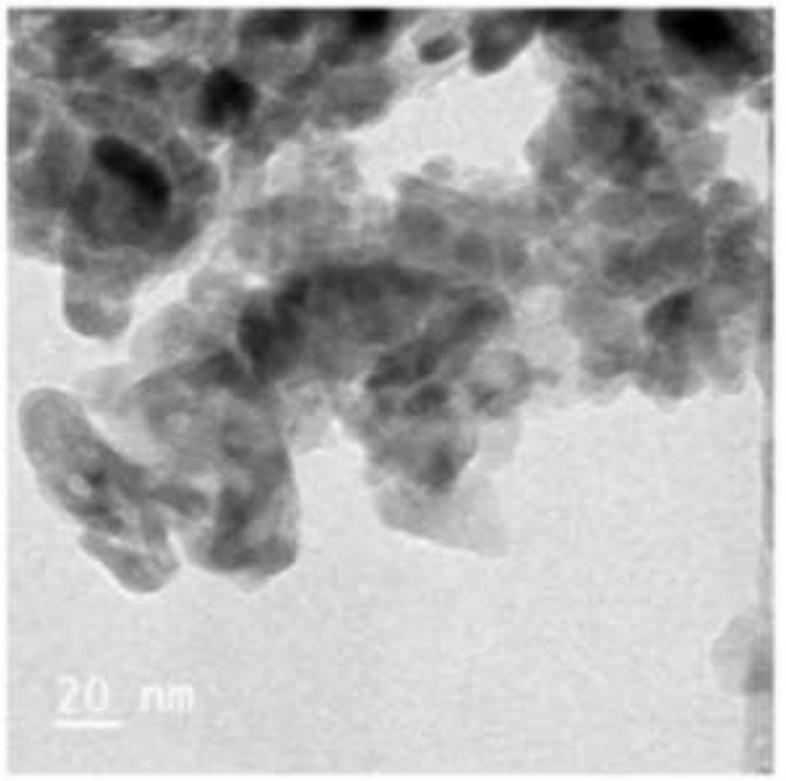

d)

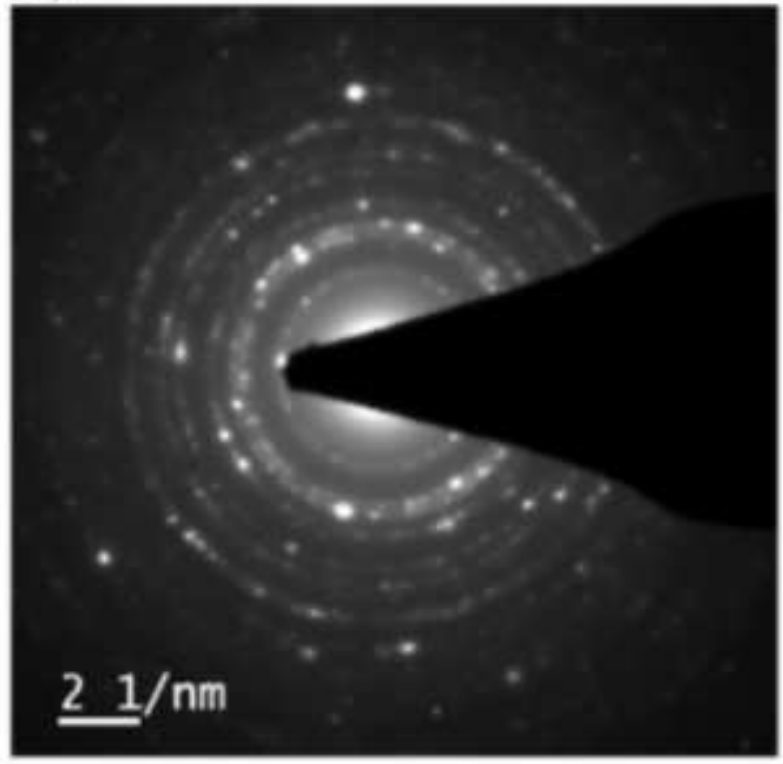

Figure 3

TEM images of a-Fe2O3 (a,b), HRTEM image of a-Fe203,SAED pattern of a-Fe2O3 (d). 


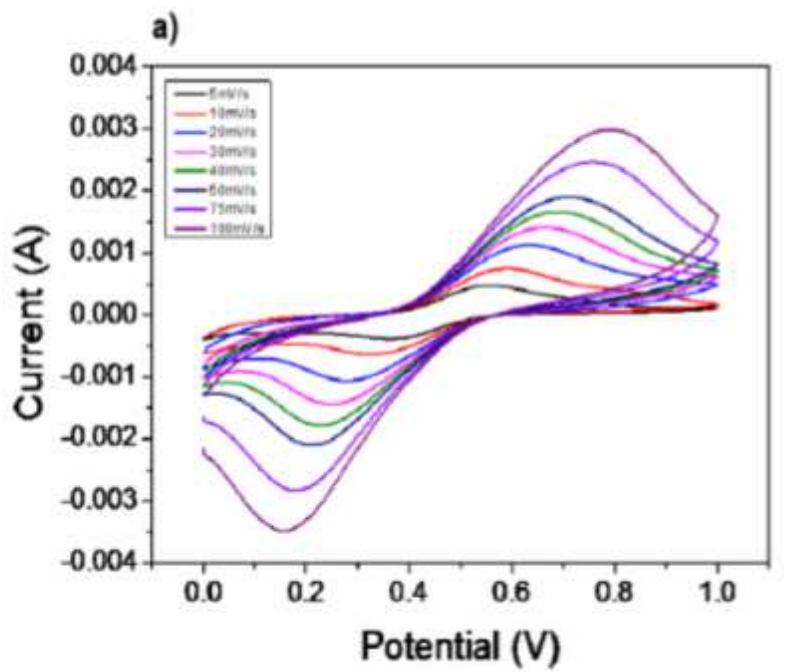

b)

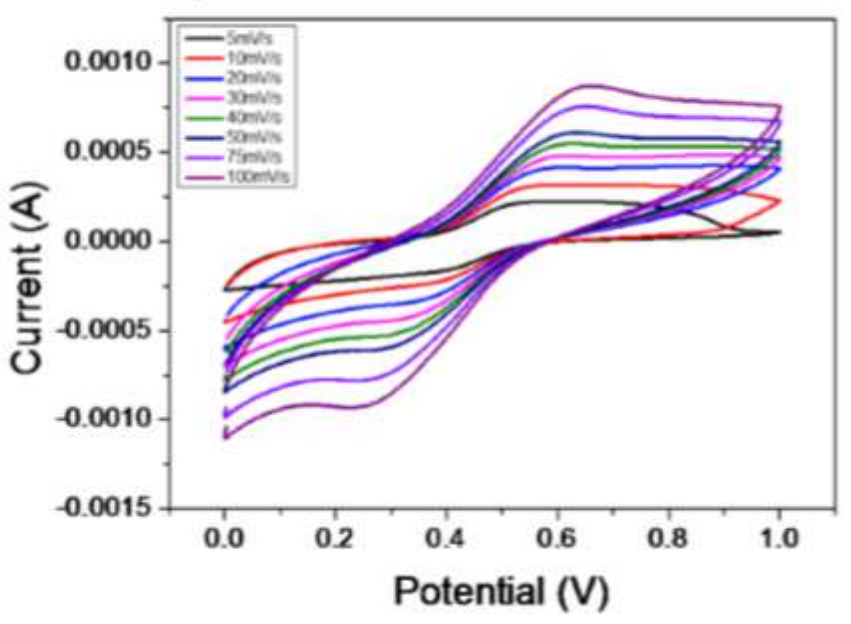

c)

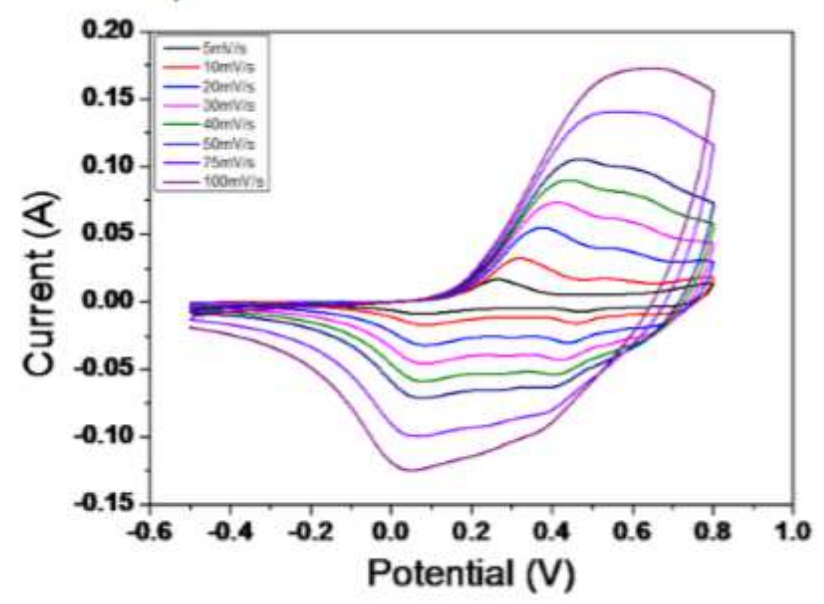

d)

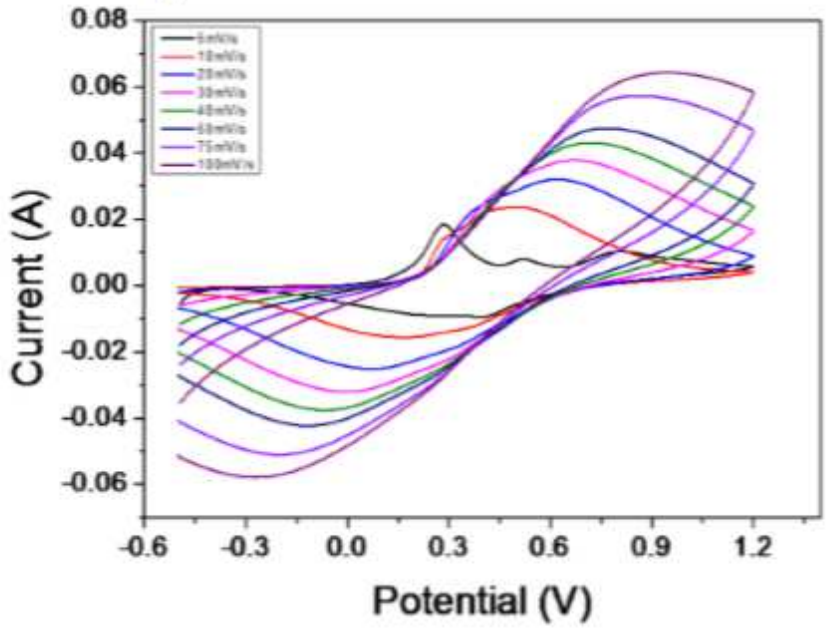

Figure 4

Cyclic voltammetry at different scan rates for CNF-Fe2O3 in $1 \mathrm{M} \mathrm{H} 2 \mathrm{SO} 4$ before cycling (a) and after 5000 cycling (b) and for PANI-Fe2O3 in 1M H2SO4 before cycling (c) and after cycling and (d) 
a)

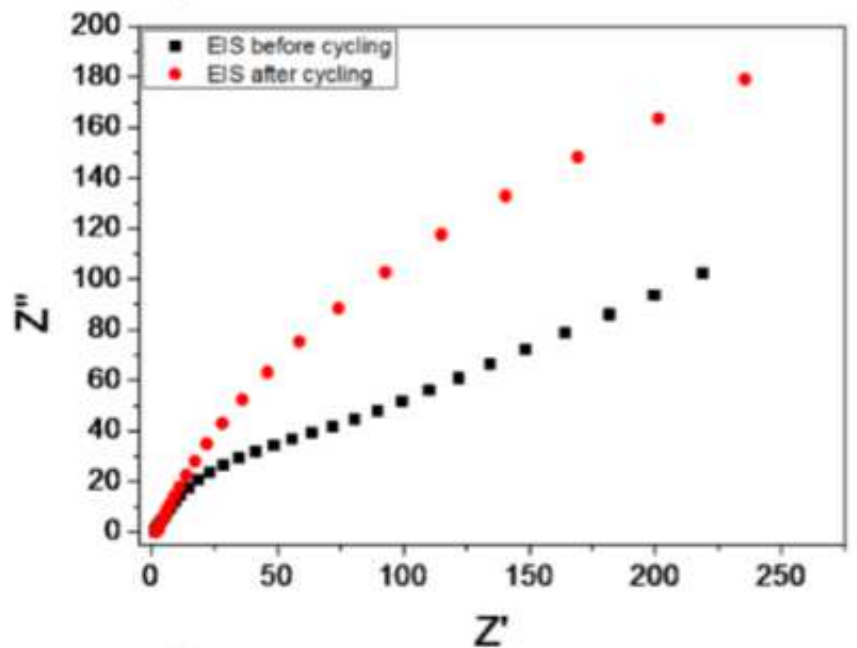

c)

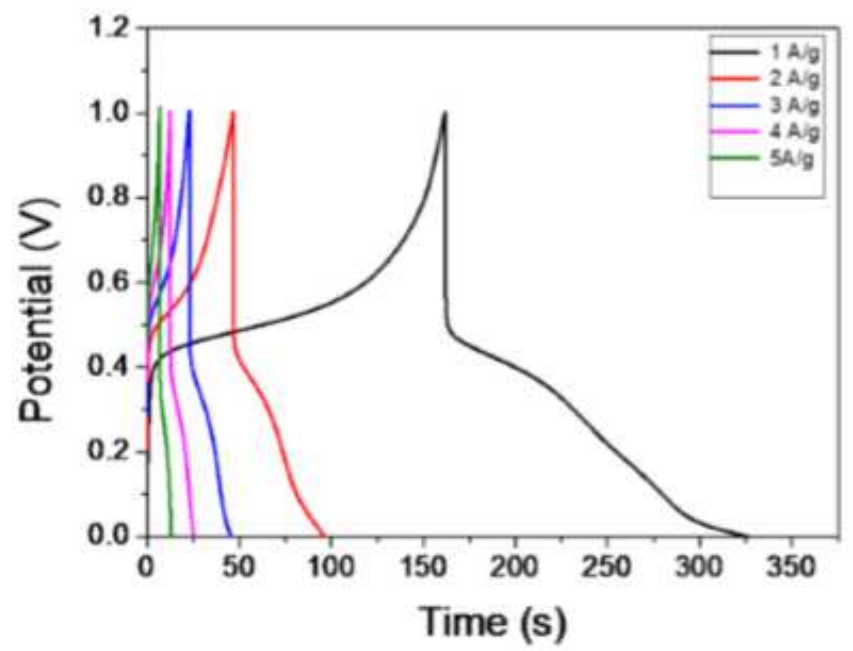

b)

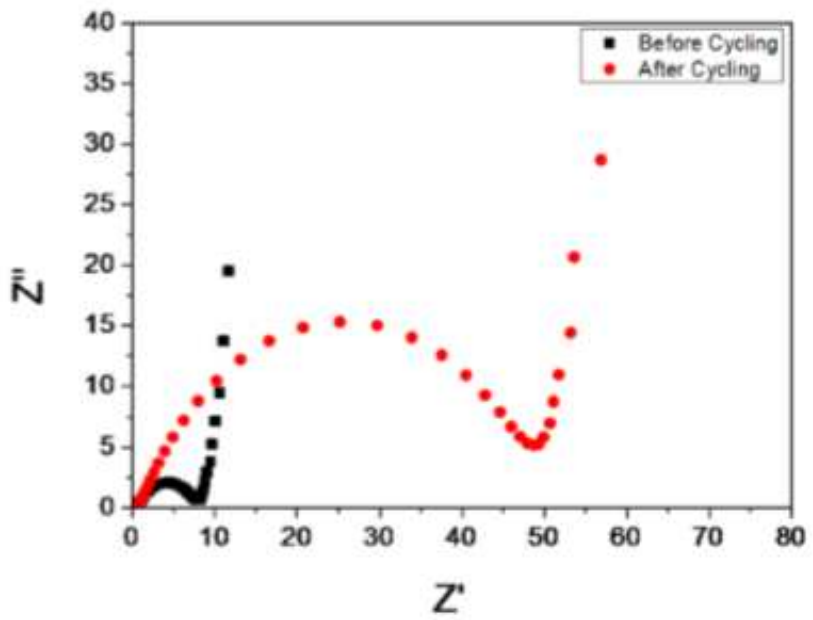

d)

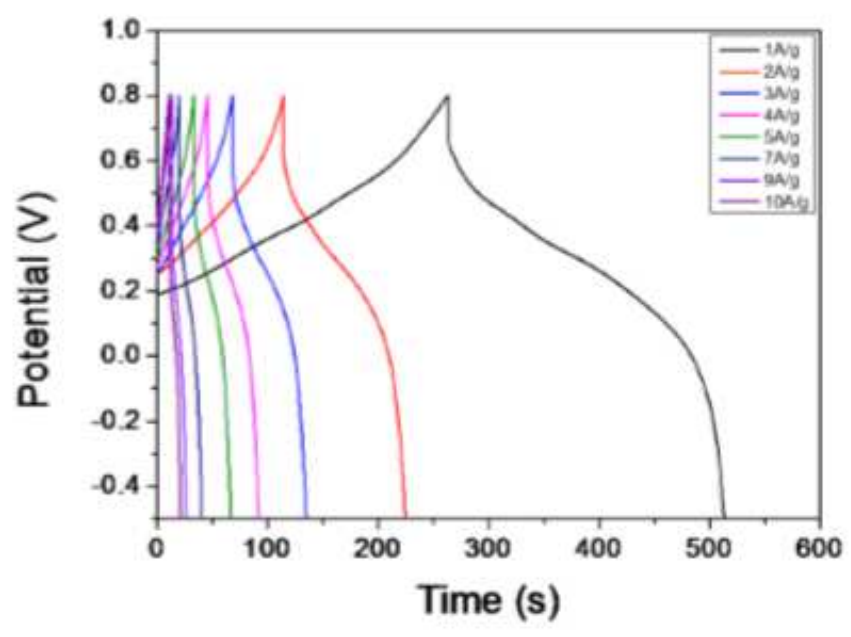

Figure 5

Cyclic voltammetry curves measured at different scan rates for PANI-Fe2O3 in 1M H2SO4 (a) before cycling and (b) after 5000 cycling; (c) EIS before and after cycling and (d) Galvanostatic charge-discharge curves at different current densities 
(a)

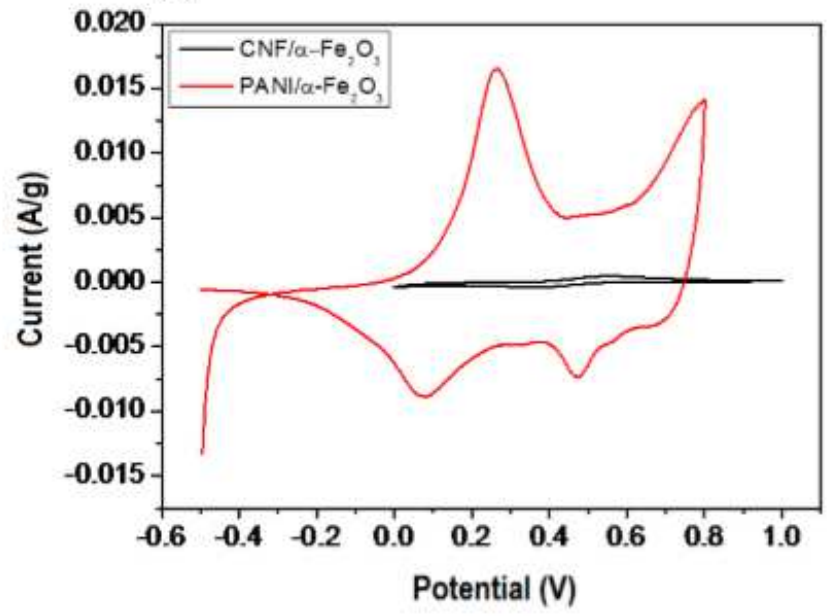

(c)

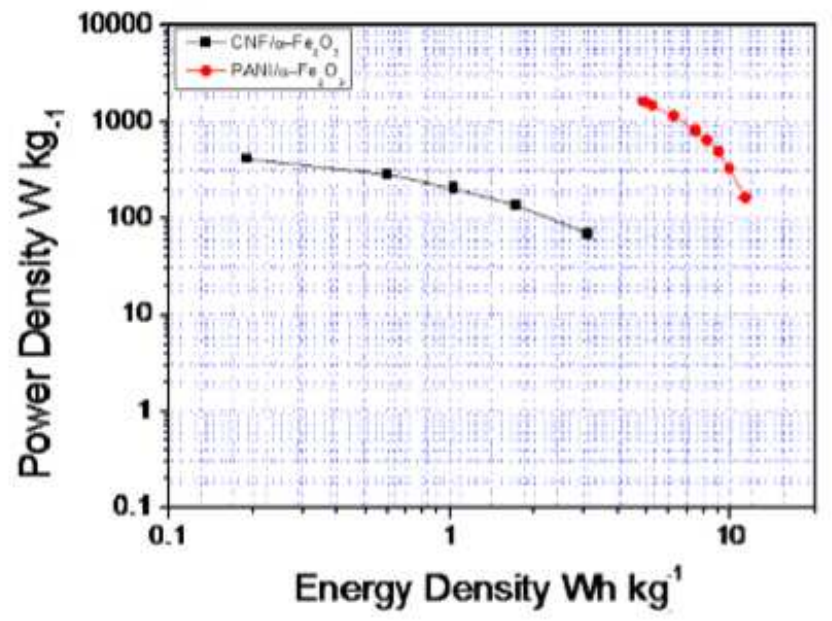

(b)

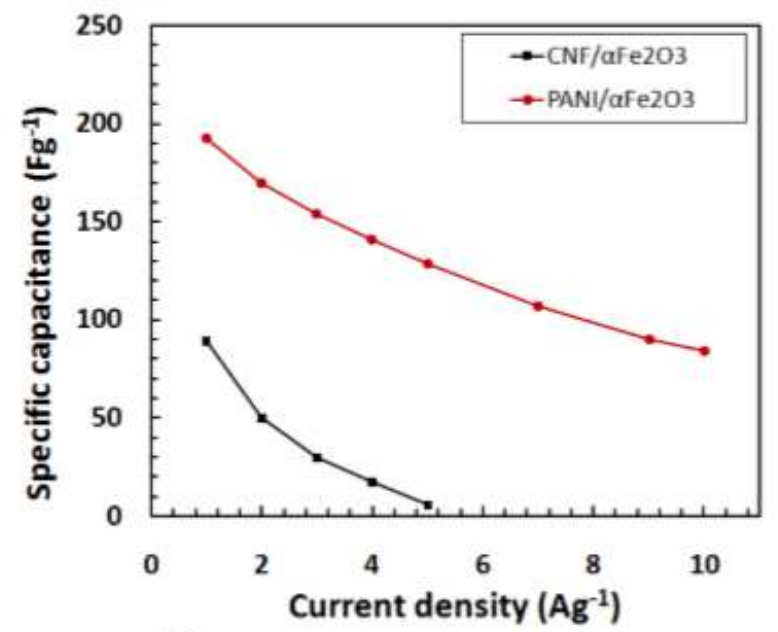

(d)

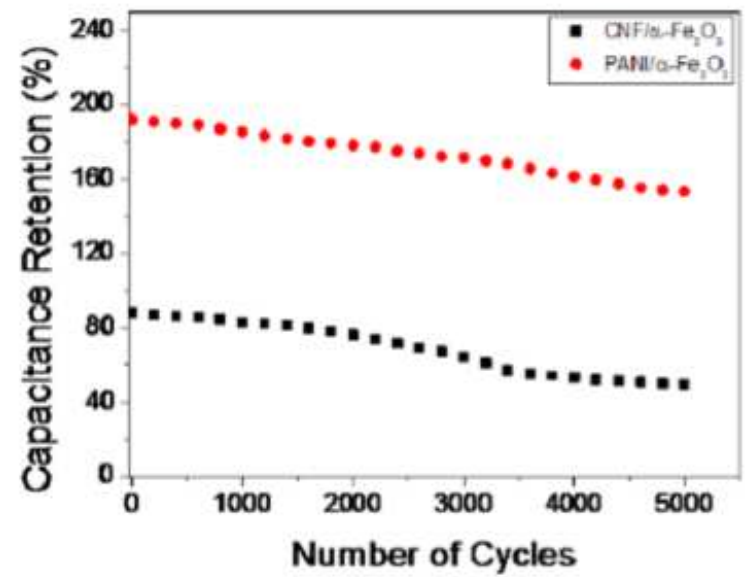

Figure 6

(a) C.V curves for a-Fe203/CNF and a-Fe203/PANI at 5mV/Sec; (b) Specific capacitance of a-Fe2O3/CNF and a-Fe203/PANI as a function of different current densities; (c) Ragone plot of a-Fe203/CNF obtained from Galvanostatic charge-discharge curve at different current densities; (d) Cycling stability of aFe203/CNF and a-Fe203/PANI over 5000 cycles at current density of 1Ag-1 